\title{
Camouflaging in autism: A systematic review
}

\author{
Julia Cook ${ }^{1}$, Laura Hull1, Laura Crane² and William Mandy ${ }^{1}$ \\ ${ }^{1}$ Research Department of Clinical, Educational, \& Health Psychology, University College London, UK \\ ${ }^{2}$ Centre for Research in Autism and Education (CRAE), UCL Institute of Education, University College \\ London, UK
}

DOI: https://doi.org/10.1016/j.cpr.2021.102080

(C) 2021. This accepted manuscript version is made available under the CC-BY-NC-ND 4.0 license https://creativecommons.org/licenses/by-nc-nd/4.0/

Author Note

Julia Cook https://orcid.org/0000-0002-8984-6656

Laura Crane https://orcid.org/0000-0002-4161-3490

Laura Hull https://orcid.org/0000-0002-8289-2158

William Mandy https://orcid.org/0000-0002-3564-5808

Correspondence concerning this article should be addressed to Julia Cook, Research Department of Clinical, Educational and Health Psychology, University College London, 1-19 Torrington Place London WCIE 6BT, UK. Email: Julia.Cook.18@ucl.ac.uk 


\section{Highlights}

- Current approaches to measuring camouflaging appear to measure 'camouflaging intent' and 'camouflaging efficacy'.

- Adults with more self-reported autistic traits report greater engagement in camouflaging.

- Sex and gender differences exist in camouflaging.

- Higher self-reported camouflaging is associated with worse mental health outcomes.

- Study designs are limited by poor participant characterisation and representativeness. 


\begin{abstract}
Some autistic people employ strategies and behaviours to cope with the everyday social world, thereby 'camouflaging' their autistic differences and difficulties. This review aimed to systematically appraise and synthesise the current evidence base pertaining to autistic camouflaging. Following a systematic search of eight databases, 29 studies quantifying camouflaging in children and adults with autism diagnoses or high levels of autistic traits were reviewed. The multiple methods used to measure camouflaging broadly fell under two different approaches: internal-external discrepancy or self-report. These approaches appear to relate to two distinct but potentially connected elements of camouflaging: observable behavioural presentations and self-perceived camouflaging efforts. While significant variation was noted across individual study findings, much of the existing literature supported three preliminary findings about the nature of autistic camouflaging: (1) adults with more self-reported autistic traits report greater engagement in camouflaging; (2) sex and gender differences exist in camouflaging; and (3) higher self-reported camouflaging is associated with worse mental health outcomes. However, the research base was limited regarding participant characterisation and representativeness, which suggests that conclusions cannot be applied to the autistic community as a whole. We propose priorities for future research in refining the current understanding of camouflaging and improving measurement methods.
\end{abstract}

Keywords: Autism, Camouflage, Camouflaging, Social Behaviour, Gender, Mental Health 


\section{Camouflaging in autism: A systematic review}

Autism Spectrum Disorder (henceforth 'autism') is a neurodevelopmental condition diagnosed on the basis of early onset social communication and social interaction difficulties as well as restricted and repetitive interests, activities and behaviours (American Psychiatric Association, 2013). Some autistic people ${ }^{1}$ employ strategies and behaviours to adapt to, and cope within, the everyday social world, thereby 'camouflaging' their autistic differences and difficulties (Attwood, 2007). Camouflaging in autism is the focus of a rapidly growing body of research; much of which aims to quantify camouflaging in children and adults as well as test associations between camouflaging and various other constructs including gender, age, autistic traits, anxious/depressive symptoms, and cognitive abilities. Currently, a lack of consensus exists regarding many of these associations. Recent discussions and commentaries highlight potential problems within the field including variations in operationalisations and measurement approaches, under-established validity and reliability across measures, and a lack of representativeness within study samples (Fombonne, 2020; Lai et al., 2020; Williams, 2021). The current systematic review provides a comprehensive and critical evaluation of the current camouflaging research base; identifying consistencies in the current evidence as well as issues that require further research.

Although definitions of camouflaging are still evolving, here we define camouflaging (also variously referred to in the literature as compensation, masking and adaptive morphing) as the employment of specific behavioural and cognitive strategies by autistic people to adapt to or cope within the predominately non-autistic social world (Cook, Crane, Hull et al., 2021; Hull et al., 2017; Lai et al., 2011; Lawson, 2020; Livingston \& Happé, 2017; Pearson \& Rose, 2021). Camouflaging may enable an

\footnotetext{
${ }^{1}$ We used identity first language (e.g., autistic person) in this paper given that it is the preference of most autistic people (Kenny et al., 2016), is less associated with stigma (Gernsbacher, 2017) and is less discriminatory towards disabled people (Bottema-Beutel et al., 2021).
} 
individual to, consciously or unconsciously, present a non-autistic social style, hide autistic characteristics, and/or minimise the visibility of social difficulties (Hull et al., 2017; Lawson, 2020). Such strategies can involve masking autistic behaviours and/or employing compensatory strategies to overcome social difficulties (Hull et al., 2019; Livingston, Shah, \& Happé, 2019). Common examples of camouflaging strategies include supressing repetitive hand movements, forcing eye contact, using conversational scripts, and using learned rules to respond to others' non-verbal behaviour. A related concept that evolved concurrently with camouflaging is that of compensation (Livingston \& Happé, 2017). Compensation has a more specific focus on cognition and refers to the use of alternative cognitive routes to demonstrate a less autistic behavioural presentation despite persisting autismrelated difficulties or differences in cognition (e.g., in social reasoning). Within the literature, compensation is generally (but not always) theorised to fall under the broader phenomena of camouflaging (Hull, Petrides, \& Mandy, 2020; Livingston, Shah, \& Happé, 2019). For clarity, in this review we use the term camouflaging to refer to compensation, masking, and adaptive morphing, since this term is most commonly used in the included research. However, we acknowledge that some autistic people prefer other terms (Lawson, 2020; Pearson \& Rose, 2021) and support calls for researchers in the field to consult with the autistic community regarding terminology moving forward (Lai et al., 2020).

Descriptions of camouflaging first appeared in clinical and autobiographical writings; usually to describe and explain the presentation of autistic girls and women, as well as the often-under-recognised diagnostic and support needs of this group. Autistic girls and women (and some boys and men) were described as using social strategies to adapt to the demands of their social environment, thereby camouflaging their social difficulties and differences (Attwood, 2007). Initially, these strategies were thought to predominately involve the effortful performance of non-autistic social behaviour, learnt over time through careful observation and imitation (Attwood, 2007; Gould \& Ashton-Smith, 2011; Kopp and 
Gillberg, 1992; Holliday Willey, 1999). However, this often exhausting and stressful camouflaging was seen as masking rather than resolving underlying social difficulties.

These clinical and autobiographical writings stimulated qualitative research aimed at conceptualising camouflaging by exploring the lived experiences of autistic girls and women (e.g., Cridland et al., 2014; Bargiela et al., 2016; Tierney et al., 2016), but also boys, men, and non-binary people (e.g., Hull et al., 2017; Livingston, Shah, \& Happé 2019). Across this research, autistic people provided rich and detailed accounts of camouflaging, significantly advancing the field. Importantly, findings suggested that many autistic people of all genders use a diverse range of camouflaging behaviours and strategies in navigating the predominately non-autistic world, often at great personal cost.

A burgeoning body of cross-sectional quantitative work has now emerged, designed to test important hypotheses generated by the qualitative camouflaging literature. In seeking to operationalise and measure camouflaging, several novel measurement methods developed in parallel. These methods broadly fall under two categories: internal-external discrepancy and self-report approaches (Hull et al., 2019). Internal-external discrepancy approaches focus on quantifying the degree to which an individual's autistic social difficulties or differences are camouflaged during an interaction; that is, quantifying the difference between an individual's 'true' autistic state and their observable behavioural presentation (e.g., Lai et al., 2017, 2019). In contrast, self-report approaches focus on quantifying an individual's use of specific camouflaging strategies or behaviour via self-reflection (e.g., Hull et al., 2019, Livingston et al., 2020). Using both internal-external discrepancy and self-report approaches, quantitative research has focused on the following questions, which form the basis of the present systematic review. 
Is camouflaging associated with having high autistic traits or an autism diagnosis?

In conceptualising camouflaging, it is important to understand the extent to which camouflaging is specific to autism (Lai et al., 2020). Autistic people report camouflaging to gain employment and education, develop and maintain friendships and romantic relationships, and avoid bullying and ostracism (Cage \& Troxell-Whitman, 2019; Hull et al., 2017). Non-autistic people similarly use social behaviour to create desirable social impressions and facilitate positive outcomes in interactions with others (i.e., impression management or self-presentation behaviours; Goffman 1959; Leary, 1995). However, compared to most non-autistic people, autistic people are more likely to experience a mismatch between their natural way of being and the demands of the social environment; the consequence of which may be stigmatisation and discrimination (Botha \& Frost, 2020; Lai \& BaronCohen, 2015; Mandy, 2019; Perry et al., 2021). Aspects of camouflaging may be unique to autism since camouflaging represents an attempt to manage this mismatch between a person's autistic way of being and the non-autistic social environment. Thus, in further refining the construct of camouflaging, it is important to investigate the degree to which camouflaging likely varies as a function of autism diagnosis. Additionally, autism is increasingly viewed as a dimensional condition, representing one end of a continuum of traits that extend throughout the general population (Robinson et al., 2016). On this basis, related to the question of whether autism is specific to those with an autism diagnosis, it is also useful to investigate whether camouflaging likely varies in those without an autism diagnoses, in line with variability in autistic traits (Hull et al., 2017).

\section{Are there sex or gender differences in camouflaging behaviours?}

The role sex and gender play in camouflaging is increasingly debated (Fombonne, 2020; Lai et al., 2020; Pearson \& Rose, 2021). Nonetheless, camouflaging is often discussed in relation to female sex/gender and offered as partial explanation for increased rates of missed or late diagnosis found amongst this group (e.g., Duvekot et al., 2017; Dworzynski et al., 2012; Head et al., 2014; Kirkovosi et al., 
2013; Lai \& Baron-Cohen, 2015; Lehnhardt et al., 2016; Shattuck et al., 2009; Whitlock et al., 2020). To date, much of this discussion has focused on male-female sex/gender differences without consideration of non-binary genders. One possibility is that due to sex-related differences in cognitive profiles, autistic females may have an enhanced ability to camouflage compared to autistic males (Lehnhardt et al., 2016). Alternatively, compared to autistic boys/men, autistic girls/women may feel more pressure to fit in socially via camouflaging, because of gender-based societal expectations and socialisation experiences (Kreiser \& White, 2014; Pearson \& Rose, 2021). A further possibility is that autistic individuals of all sexes and genders, including those outside the gender binary, may engage in similar levels of camouflaging due to a mismatch in person-environment fit and related stigma and discrimination. In moving the field forward, it is important to establish a consensus regarding the role of sex and gender in camouflaging.

\section{Are particular cognitive abilities or processes associated with camouflaging?}

A considerable degree of heterogeneity exists amongst autistic people regarding general cognitive ability as well as specific cognitive strengths and weakness (Charman, 2011). Relevant to conceptualising camouflaging is the need to investigate cognitive abilities associated with camouflaging. IQ and executive functioning, in particular, have been hypothesised as supporting camouflaging via the facilitation of compensatory cognitive strategies (e.g., using learned social rules or scripts; Livingston, Colvert, et al., 2019). It is therefore useful to explore if individual differences in such cognitive abilities account for variability in camouflaging amongst autistic people.

\section{Is camouflaging related to current age or age at diagnosis?}

In conceptualising camouflaging, it is important to understand changes in camouflaging across the lifespan. Qualitative research suggests that children, adolescents, and adults engage in camouflaging, although perhaps to varying degrees (e.g., Dean et al., 2017; Halsall et al., 2021; Hull et al., 2017). Age-related fluctuations in camouflaging may relate to, for example, changes in cognitive development, social demands and experiences, and mental health; all of which likely occur throughout 
development and into adulthood (Hull, Petrides, \& Mandy, 2021). Moreover, age-related changes in constructs that may be related to camouflaging (e.g., impression management) are known to occur in non-autistic people (e.g., Pledger, 1992). Thus, in further characterising camouflaging, it is important to investigate the degree to which camouflaging varies with age. Additionally, a later age at diagnosis may be associated with a greater tendency to adapt to social demands and camouflage social difficulties (Lai \& Baron-Cohen, 2015). Alternatively, having had additional time to form a strong autistic social identity, those diagnosed younger in life may feel less pressure to conform to non-autistic social standards via camouflaging (Cage \& Troxell-Whitman, 2020). To better understanding fluctuations in camouflaging across the lifespan, it is important to consider the role of age at diagnosis.

\section{What is the relationship between camouflaging and mental health or wellbeing outcomes?}

Consistently high rates of mental health problems are found amongst autistic people across the lifespan (Lever \& Geurts, 2016; Simonoff et al., 2008), which are associated with lower social and adaptive functioning (Moss et al., 2015), employment and educational difficulties (Keen et al., 2016; Lounds Taylor et al., 2015), and poorer quality of life (Adam et al., 2019). In the qualitative camouflaging literature, autistic people consistently describe camouflaging as being exhausting and associated with feelings of anxiety, stress, sadness, and identity confusion (Bargiela et al., 2016; Hull et al., 2017; Tierney et al., 2016). Camouflaging may be one factor that makes autistic people more vulnerable to mental health problems. Thus, investigating links between camouflaging and mental health is important in improving the well-being and life opportunities of autistic people.

\section{Previous Reviews}

Given the early nature of camouflaging research, a lack of consensus remains regarding many of the aforementioned questions. Previous reviews, focused on camouflaging in autistic females, provide partial insights. In an early examination of the field, Alley (2019) reviewed eight studies to identify and 
explore camouflaging in autistic females. More recently, a systematic review of 13 studies was conducted by Tubío-Fungueriño (2021). This latter review examined camouflaging in autistic females with a focus on the camouflaging process, as well as camouflaging causes and consequences. Finally, Hull, Petrides, \& Mandy (2020) completed a narrative review of research examining the female autism phenotype and camouflaging. Across these three reviews, preliminary evidence suggested that for autistic females: camouflaging abilities may be associated with self-control, empathy, and/or feedback abilities; motivators of camouflaging may include societal expectations and feelings of loneliness or isolation; and consequences of camouflaging may include late findings cannot be generalised to individuals of all sexes and genders.

Moreover, recent discussions and commentaries (Fombonne, 2020; Lai et al., 2020; Williams 2021) have highlighted several potential problems within camouflaging literature that have not been addressed in the above reviews. First, significant variations in the operationalisation and measurement of camouflaging may mean that making comparisons between, and drawing conclusion across, studies is difficult. Second, advancement of the field requires the establishment of valid and reliable measures of camouflaging; yet, at the time of earlier reviews, much of this work was still ongoing. Third, a lack of representativeness in study samples may limit the extent to which findings can be generalised to the wide range of people on the autism spectrum. To date, no review has systematically identified and described methods of measuring camouflaging, nor has it systematically examined the measurement properties of these methods. Further, no review has systematically examined and described the characteristics of participants included in camouflaging studies. Thus, a critical evaluation of camouflaging research related to all sexes and genders is now needed to identify consistencies in the current evidence as well as gaps that require further research.

\section{The Present Review}


The present systematic review aims to: systematically review studies quantitatively examining camouflaging in children and adults of all sexes and genders who have an autism diagnosis or high autistic traits; report detailed summary information on the characteristics of study participants; summarise measurement methods, including measurement properties; and assess the quality of studies. In addition, to identify consistencies within the current evidence base as well as avenues for future research, we examine and summarise study findings based on the five aforementioned research questions.

\section{Review Methods}

\section{Search Strategy and Selection Criteria}

This review protocol was registered online with PROSPERO, the international prospective register of systematic reviews (registration number: CRD42019141410). Our review proceeded as planned except that one research question ("Is camouflaging associated with having high autistic traits or an autism diagnosis?") was added after the search, in response to multiple studies presenting data on camouflaging, autistic traits, and diagnostic status. The most current version of the Preferred Reporting Items for Systematic Reviews and Meta-Analyses (PRISMA) guidelines for conducting systematic reviews was followed throughout the review process (Page et al., 2021). In consultation with a bioscience and psychology subject librarian, the following databases were searched from inception to October 2020 for publications on autism and camouflaging: Medline (Ovid), Embase (Ovid), APAPsycINFO (Ovid), Web of

Science and Scopus. The search strategy involved a combination of keywords and controlled vocabulary terms and was modified for use with each database (see Appendix A for search strategies). No filters, restrictions, or limits were applied at this stage. To identify additional unpublished and emerging research, a targeted search of the following grey literature databases was conducted using keywords in October 2020: ProQuest Dissertations and Theses Global, Google Scholar, and PsyArXiv. Experts in the field and authors of relevant theses, conference abstracts/proceedings, and preprint articles were then 
contacted to identify any full text articles accepted (but not yet published) in peer reviewed academic journals. An updated search employing the same initial search methods was then conducted on $13^{\text {th }}$ May 2021. Reference lists of included studies and relevant past systematic reviews were manually checked for additional relevant research. References were managed using Endnote and Rayyan (Ouzzani et al., 2016). Duplicates were removed iteratively using Endnote's duplication identification strategy, and then manually.

$\mathrm{JC}$ initially screened the titles and abstracts of all identified articles using broad inclusion/exclusion criteria to ensure any potentially relevant publications were retained for further evaluation. Publications included at this stage discussed any aspect of camouflaging in any population. No publication or language restrictions were applied. After exclusion of research according to these broad criteria, the full texts of remaining publications were evaluated for inclusion independently by JC and LH. Studies adhering to the inclusion criteria in Table 1 were included in the review. Discrepancies regarding the eligibility of studies were reconciled between JC and LH, with WM and LC.

[insert table 1 here]

\section{Data Extraction}

Using a standardised form developed for this study, data on study information, participant characteristics, methods of measuring camouflaging, and study results were extracted for studies meeting the inclusion criteria. Each author independently extracted data for $\approx 25 \%$ of included studies. Each author then cross-checked data for a separate $\approx 25 \%$ of included studies. Discrepancies were discussed and resolved via consensus. Missing data were requested from study authors.

\section{Quality Assessment}

Study quality was assessed using the Mixed Methods Appraisal Tool (MMAT; Hong et al., 2018). The MMAT is designed for use in mixed studies reviews and is suitable for use with qualitative research, randomized controlled trials, non-randomized studies, quantitative descriptive studies and mixed 
methods studies. The five quality criteria applied to studies using the MMAT vary according to study design. Outcomes for each criterion are defined as 'yes' meets criteria, 'no' does not meet criteria, or 'can't tell' where appropriate information was not reported. In line with current literature suggesting that summed quality scores do not provide a meaningful index of study quality (e.g., Herbison et al., 2006), the authors of the MMAT discourage the calculation of an overall quality score for each study and instead suggest that a more detailed description of the criterion ratings are presented. Each study was independently rated by two reviewers (i.e., either JC and LC or WM and LH). Reviewers did not assess studies for which they were also authors, with the exception of one study (Cook, Crane, Bourne et al., 2021) on which all four reviewers were authors. To ensure consistency, pairs of reviewers met separately and then as a whole group to discuss their interpretation and application of each of the MMAT criteria regarding the included studies. Discrepancies in ratings were discussed and resolved by consensus.

\section{Overview of Included Studies}

\section{Results}

As can be seen in Figure 1, after removal of duplicates, 2160 unique citations were screened for eligibility, of which 104 full-text articles were reviewed and 29 studies were identified as eligible for inclusion in the systematic review. Where additional analyses of study data were presented across multiple articles, all articles were included. Six of the studies included in the two previous systematic reviews (Allely, 2019; Tubío-Fungueiriño et al., 2021) did not quantitatively measure camouflaging and thus were not included in the current review (see Appendix B for further details).

[insert Figure 1 here]

Details of included studies are provided in Tables 2, 3, 4, and 5. Eighteen of the included studies examined camouflaging in adults, and 11 examined camouflaging in children and adolescents. Studies were either open to individuals worldwide to participate (but conducted in English; n=9) or were restricted to individuals located in the UK $(n=10)$, USA $(n=8)$, Australia $(n=1)$, or Poland $(n=1)$. The 
majority of studies $(n=23)$ involved solely quantitative methodologies and a further three used mixed methods designs (Cage et al., 2018; Jedrzejewska \& Dewey, 2021; Livingston et al., 2020). Three studies involving chiefly qualitative design were included because each included a quantitative measure of camouflaging (Cook, Crane, Bourne et al., 2021; Hull et al., 2017; Livingston, Shah, \& Happé et al., 2019).

\section{Quality Assessment}

Results of the quality assessment using the MMAT are detailed in full in Appendix C. Although the overall quality of included studies was sound, several specific methodological issues were common across the quantitative and mixed-methods studies. Most studies failed to gain a representative sample of autistic participants $(n=23)$ and/or did not provide a description of participant flow (e.g., an indication of the number of people who started, but failed to finish, an online questionnaire; $n=17$ ). Less common methodological issues included: failing to consider or account for any potential betweengroup differences in demographic variables, in design or analysis $(n=10)$; failing to control for autistic traits in analyses between autistic and non-autistic groups $(n=2)$; using measures not designed for autistic people/a specific age group of autistic people and failing to provide information regarding the suitability of these measures and/or failing to provide reliability data for these measures with the study sample $(n=4)$; and using an ad hoc method of quantifying camouflaging or compensation, that is, providing participants with camouflaging or compensation scores based on text responses to open ended questions $(n=2)$.

\section{Participant Characteristics}

Table 2 provides an overview of participant characteristics for participants with autism diagnoses or high autistic traits. There were four sets of studies in which samples were partially or fully duplicated (Hull et al., 2019; Hull, Lai, et al., 2020; Hull, Levy, et al., 2021; Jorgenson et al., 2020;

Bernardin et al., 2021; Lai et al., 2017, 2019; Livingston, Shah, \& Happé, 2019; Livingston et al., 2020). In 
these instances, only information from one study (the study with the largest N) was counted when calculating aggregated participant characteristics. In total, 2254 autistic adults (clinically diagnosed or self-identifying) and adults with high levels of autistic traits were included across all studies (sample sizes ranged from $\mathrm{N}=17$ to $\mathrm{N}=354$ ). Adults ranged in age from 16 to 82 with a mean age of 36.47 years. The majority of participants reported female sex or identified as women ${ }^{2}(60.1 \%)$ and were formally diagnosed with autism (95.9\%). Further characterisation of adult participants was generally poor. Most participants in the eight studies reporting ethnic group/race were white (86.1\%). General anxiety (54.8\%) and depression (53.1\%) were common amongst participants in the five studies reporting cooccurring mental health conditions. Participants were typically diagnosed in adulthood ( $M=32.98$ years) across the seven studies reporting mean age at diagnosis. Only four studies measured IQ and participants in these studies were of average to above average intelligence (Full Scale IQ, $M=112.35$ ). Most studies recruited adult participants via advertisements distributed through social media, autism charities and support groups, and/or research databases.

Child and adolescent samples ranged from $\mathrm{N}=33$ to $\mathrm{N}=236$ with a total of 1077 children and adolescents with an autism diagnosis or high levels of autistic traits included across all studies. Child/adolescent participants ranged in age from 5 to 18 years with a mean age of 11.90 years. Most participants were of male sex or identified as boys ${ }^{3}(62.9 \%)$ and were formally diagnosed with autism (94.7\%). Mean Full Scale IQ was in the average range (99.93). Further characterisation of child/adolescent participants was frequently lacking. Most participants in the two studies reporting ethnic group/race were white (75.8\%). Almost half of the participants in the one study reporting

\footnotetext{
${ }^{2}$ In describing sex and gender of participants, adult studies reported: gender only $(n=8)$; sex and gender $(n=3)$; sex only $(n=2)$. In the remaining two studies it was unclear if the measurement of sex/gender reported referred to sex or gender.

${ }^{3}$ In describing sex and gender or participants, child studies reported sex only $(n=6)$; what was termed sex/gender by authors $(n=2)$; and gender only $(n=2)$. In one study it was unclear if measurement of sex/gender reported referred to sex or gender.
} 
comorbidities had co-occurring diagnoses (40.7\%). Studies recruited child and adolescent participants via a variety of means including via autism and mental health clinics, research centres and databases, schools, birth records, a social skills trial, social media, and word of mouth. Specific participant characteristics reported in each included study are in Appendix D.

[insert Table 2 here]

\section{Camouflaging Measures}

Included studies quantified camouflaging using two different measurement approaches: internal-external discrepancy approaches, or self-report approaches. A range of terms (i.e., masking, camouflaging, and compensation) were used to describe measures. Throughout this review, we used the term camouflaging to refer to the related concepts of camouflaging, compensation, and masking. However, to ensure accuracy when describing specific study measures, we use the terminology used by the relevant study authors in this section.

\section{Internal-External Discrepancy Approaches}

As can be seen in Table 3, three adult studies and six child/adolescent studies used internal-external discrepancy approaches. Internal-external discrepancy approaches aim to measure camouflaging by quantifying differences between internal ('true') autistic states and observable behavioural presentations (Lai et al., 2017, 2020). Across studies, various self- or parent-report measures of autistic traits and/or performance-based measures of social cognition were used as proxy measures of 'true' autistic status while observer/computer rated measures of social behaviour were used to assess external behavioural presentation. Two studies calculated individual camouflaging scores by quantifying the difference between individuals' scores on a self-report measure of autistic traits/a performancebased measure of Theory of Mind (ToM) and an observer rated measure of social behaviour (Lai et al., 2017 , 2019). One study calculated individual camouflaging scores by quantifying the difference between individuals' scores on a self-report measure of autistic traits and an observer-rated measure of social 
behaviour (Schuck et al., 2019). Three studies classified participants into distinct compensation or 'compensatory camouflaging' ability groups (e.g., high, low, deep, or unknown) based on scores on performance-based measures of ToM (splitting participants based on the median or mean score of the sample or the median score of a non-autistic reference group) and observer rated measures of social behaviour or reciprocity (splitting participants on median or mean scores of the sample; Corbett et al., 2020; Livingston, Colvert, et al., 2019; Wood-Downie et al., 2020). Four studies compared differences between groups hypothesized to differ in camouflaging ability (i.e., boys and girls) in parent-rated social communication skills/autism characteristics and observer rated social behaviour/s or reciprocity (ParishMorris et al., 2017; Ratto et al., 2018; Rynkiewcz et al., 2016; Wood-Downie et al., 2020). Two of these studies further explored camouflaging-related differences in the quality of social behaviour exhibited by autistic girls and boys by comparing differences in social behaviour between autistic and non-autistic girls and autistic and non-autistic boys (Parish-Morris et al., 2017; Wood-Downie et al., 2020).

[insert Table 3 here]

\section{Self-Report}

As can be seen in Table 4, 19 studies used self-report measures of camouflaging. Self-report approaches aim to measure camouflaging by quantifying individuals' self-perceived engagement in camouflaging. One additional study used a parent-report measure of masking. The precise nature of these self-report and parent-report methodologies and instruments varied significantly between studies.

Nine adult studies and four child/adolescent studies used the Camouflaging Autistic Traits Questionnaire (CAT-Q; Hull et al., 2019). The CAT-Q is a 25-item self-report questionnaire designed to measure camouflaging strategies and behaviours (e.g., "I adjust my body language or facial expressions so I appear relaxed") across three subscales (compensation, masking, and assimilation) with higher scores indicating greater levels of camouflaging. Items on the CAT-Q were developed based on a qualitative study exploring the camouflaging experiences of autistic adults. The CAT-Q was validated in a 
sample of 832 autistic and non-autistic adults (Hull et al., 2019). Test-retest reliability reported in the validation study was good ( $r=0.77)$. Internal consistencies for the Total CAT-Q and subscale scores in included studies ranged from $\alpha=0.79$ to $\alpha=0.94$. Whilst yet to be validated for use with autistic adolescents, four studies using the CAT-Q involved adolescent samples (Bernadin et al. 2021; Hull, Petrides, \& Mandy, 2021; Jedrzejewska \& Dewey, 2021; Jorgenson et al., 2020). Internal consistency for the total CAT-Q and subscale scores ranged from $\alpha=0.81$ to $\alpha=0.91$ across these four studies. One study also included a modified version of the CAT-Q measuring camouflaging strategies and behaviours used in the social media environment (Jedrzejewska \& Dewey, 2021).

Two studies used modified versions of the Girls Questionnaire for Autism Spectrum Conditions (GQ-ASC; Attwood et al., 2011). One study used the Questionnaire for Autism Spectrum Conditions (QASC) - a version of the GQ-ASC modified for use with males and females (Ormond et al., 2018). The Masking subscale on Q-ASC measures a parent's perception of their child's masking behaviours via five items (e.g., "Does s/he have a facial 'mask' that hides his/her social confusion?”). Internal consistency for the Social Masking scale was $\alpha=.61$. Another study used a version of the GQ-ASC modified for use with women (Brown et al., 2020). The camouflaging scale on this version of the GQ-ASC includes four items measuring self-reported engagement in camouflaging behaviours (e.g., "I adopt a different persona in different situations"). The structure of this version of the GQ-ASC was investigated using principal components analysis in a sample of 672 autistic and non-autistic women. Internal consistency for the Camouflaging subscale was $\omega=0.67$.

Livingston et al. (2020) used the Compensation Checklist, a list of 31 strategies (e.g., "Mimic phrases, gestures, facial expressions, tone of voice picked up from other people and/or TV/film/book characters") divided in to four categories (masking, shallow compensation, deep compensation, and accommodation) created based on a qualitative study of compensatory strategies (reported in Livingston, Shah, \& Happé, 2019). Individuals in the same dataset (reported in Livingston et al., 2020) 
were then given compensation scores based on the number of times they referenced specific compensation strategies and behaviours in their text responses with greater compensation scores indicating a higher number of strategies and behaviours referenced. The greatest lower bound reliability for the Total Compensation Score was glb $=0.82$.

Authors in three studies created a single question or short sets of questions to measure camouflaging. Cassidy et al. (2018) created a set of four questions measuring engagement in camouflaging (yes/no), camouflaging areas (e.g., work, educational settings, social gatherings, etc.), camouflaging frequency (i.e., percentage of social situations a person is camouflaging in), and camouflaging amount (i.e., amount of the day spent camouflaging). Scores were summed for camouflaging areas, frequency, and amount; with higher total scores indicating more camouflaging. Reported internal consistency for the questions was $\alpha=.75$. Cage and Troxell-Whitman (2019) measured the frequency with which participants engaged in two overarching camouflaging contexts (formal and interpersonal contexts) identified from an initial set of 22 camouflaging contexts. Participants were then classified into three groups: consistently low camouflagers (camouflaging low in both contexts); switchers (camouflaging high in one context but low in the other); and consistently high camouflagers (camouflaging high in both contexts). Internal consistency for the set of camouflaging contexts was $\alpha=0.95$. Hull et al. (2017) included a single item quantitatively measuring engagement (yes/no) in camouflaging.

Two studies provided quantitative data measuring camouflaging generated from qualitative data sets. One study provided quantitative data regarding the number of participants who spontaneously reported camouflaging in text responses to questions about autism acceptance and mental health (Cage et al., 2018). Another study provided quantitative data regarding the total number of participants who endorsed themes, three of which were types of compensation behaviours or 
strategies (i.e., shallow compensation, deep compensation, and behavioural masking) in text responses to open ended questions about compensation (Livingston, Shah, \& Happé, 2019).

[insert Table 4 here]

\section{Study Findings}

An overview of the camouflaging evidence base is shown in Table 5. Results regarding specific study findings are described and discussed further below, based on the five identified research questions. Again, to ensure accuracy when describing specific study measures, we use the camouflaging terminology used by the relevant study authors in this section.

[insert Table 5 here]

\section{Is Camouflaging Associated with having High Autistic Traits or an Autism Diagnosis?}

Adults. Four studies examined associations between camouflaging, diagnostic status, and/or autistic traits in adults using self-report measures. Overall, results suggested that higher levels of self-reported camouflaging are associated with having an autism diagnosis or higher autistic traits in adult samples.

In a large sample of adults, formally diagnosed autistic individuals scored higher than nonautistic individuals on the CAT-Q Total and subscale scores (Hull et al., 2019). Associations between CATQ subscale scores and autistic trait severity varied somewhat in this sample. However, higher overall scores on the CAT-Q were associated with higher autistic traits for both formally diagnosed and nonautistic individuals. Autistic (formally diagnosed and self-identifying) and non-autistic adults similarly described either deep compensation, shallow compensation, or behavioural masking strategies at least once in text responses to open ended questions (Livingston, Shah, \& Happé, 2019). However, formally diagnosed autistic individuals described a greater total number of compensation strategies compared to non-autistic individuals (Livingston et al., 2020). This association was not maintained after accounting for autistic traits and education, suggesting that the relationship between camouflaging and autism diagnosis may be driven by autistic traits. Finally, in a large sample of cisgender and transgender 
women, formally diagnosed autistic women scored higher than non-autistic women on the Camouflaging subscale of the modified GQ-ASC (Brown et al., 2020). However, higher scores on the Camouflaging subscale were only associated with higher autistic traits for non-autistic women.

A further three studies examined associations between self-reported camouflaging and social concepts related to diagnosis: autistic identity, experiences of autism acceptance, disclosure, and stigma. Across these studies, evidence suggested that experiences of stigma and not feeling accepted by others was associated with increased camouflaging (Cage et al., 2018; Perry et al., 2021) whilst high autistic identification and open disclosure of one's diagnosis may be associated with reduced camouflaging (Cage \& Troxell-Whitman, 2020).

Children and Adolescents. In child and adolescent samples, two studies used self-report measures to compare camouflaging between autistic and non-autistic adolescents. Results across these two studies were inconsistent. Jorgenson et al. (2020) found that while autistic and non-autistic adolescents displayed some variation regarding CAT-Q subscales, autistic adolescents did not score more highly overall on the CAT-Q than non-autistic adolescents. In contrast, Jedrzewska \& Dewey (2021) reported that autistic adolescents demonstrated significantly higher Total CAT-Q scores than non-autistic adolescents in offline (but not online) settings.

\section{Are there sex or gender differences in camouflaging behaviours?}

Adults. Nine of the included studies using adult samples reported data relating to sex or gender differences in camouflaging using internal-external discrepancy or self-report approaches. Five of these studies examined gender differences, two examined sex differences, and two examined what they termed sex/gender differences. To ensure accuracy, when describing study results, we use the sex or gender terms used by the relevant study authors. Results across these studies varied, but evidence from five of the nine studies suggested that those reporting male sex or identifying as men camouflaged less than those reporting female sex or identifying as women. Additionally, results from one study suggested 
that those reporting non-binary genders camouflaged more than those identifying as men (Perry et al., 2021).

Results of three exploratory studies using predominately qualitative methodologies were not suggestive of sex or gender differences in camouflaging (Cage et al., 2018; Hull et al., 2017; Livingston et al. 2020). However, results of four studies using psychometrically rigorous methods of quantification (i.e., continuous rating scales) generally supported sex or gender differences. When examining sex differences in camouflaging frequency and pervasiveness, compared to autistic males, autistic females reported camouflaging across more situations, more frequently and for more of the time (Cassidy et al., 2018). Regarding gender, Hull, Lai, et al. (2020) found that autistic women demonstrated higher Total CAT-Q scores than autistic men after accounting for age and autistic-like traits. Gender differences in self-reported camouflaging between men, women, and non-binary people were not found, however, the sample was underpowered for non-binary people. Perry et al. (2021) also reported that gender was a suggestive predictor of camouflaging such that identifying as female or non-binary predicted higher Total CAT-Q scores. However, Cage and Troxel-Whitman (2019) found no gender differences on the Total CAT-Q score between autistic men or women.

The two studies investigating what they termed sex/gender differences using the internalexternal discrepancy approach found that autistic women demonstrated higher camouflaging scores than autistic men (Lai et al., 2017; Schuck, et al., 2019).

Children and Adolescents. Nine of the included studies reported data related to sex or gender differences in camouflaging in autistic children and adolescents. Five studies reported sex differences; two reported gender differences; and two studies reported what the authors termed sex/gender differences. Again, findings were mixed, but evidence from seven of the nine studies suggested that through childhood and adolescence, those reporting female sex or identifying as girls camouflage more than those reporting male sex or identifying as boys. 
Across five internal-external discrepancy studies investigating sex or sex/gender differences, autistic females with high autistic traits and/or autism diagnoses demonstrated less autistic social behaviour than males with autistic traits and/or autism diagnoses, despite having equivalent (or poorer) social communication skills, autistic traits, and ToM abilities (Corbett et al., 2020; Parish-Morris et al., 2017; Ratto et al., 2018; Rynkiewcz et al., 2016; Wood-Downie et al., 2020). In contrast, Livingston, Colvert, et al. (2019) found no gender differences between compensation groups, although the sample was underpowered for females.

More variation existed across the three studies using self/parent-report methodologies. Regarding sex, autistic females engaged in more parent-reported masking behaviours than autistic males on the Masking subscale of the Q-ASC (Ormond et al. 2018). Similarly, autistic and non-autistic adolescents identifying as female gender reported engaging in more camouflaging online (using the CATO-Q) than those who identified as male gender (Jedrzejewska \& Dewey, 2021). However, no sex or gender differences were found for autistic adolescents using the CAT-Q in offline contexts (Jorgenson et al., 2020; Jedrzejewska \& Dewey, 2021).

\section{Are particular cognitive abilities or processes associated with camouflaging?}

Adults. The two small-scale studies exploring associations between camouflaging and cognitive abilities in autistic adults via internal-external discrepancy measurement approaches yielded inconsistent results. The sole adult study reporting data on camouflaging and IQ found no association between camouflaging and Full-Scale IQ, Verbal IQ, or Performance IQ (Lai et al., 2017). With regard to executive functioning abilities, Schuck et al. (2019) found no relationship between camouflaging and executive functioning, while Lai et al. (2017) suggested that higher camouflaging scores may be associated with better executive functioning abilities for autistic women but not autistic men.

Children and Adolescents. Four included studies examined relationships between cognitive abilities and camouflaging in children and adolescents using internal-external discrepancy and self- 
report measurement approaches. Results regarding associations between camouflaging and IQ were inconsistent. However, there was some evidence to suggest that higher camouflaging was associated with better executive functioning abilities.

Three studies used internal-external discrepancy approaches to stratify children/adolescents into compensation ability groups. Livingston, Colvert, et al. (2019) found high compensators demonstrated significantly higher Full Scale IQ and Verbal IQ (but not Non-Verbal IQ) scores than low compensators. Similarly, using a smaller sample, Wood-Downie et al. (2020) reported a non-significant trend towards high 'compensatory camouflagers' demonstrating higher Full Scale IQ scores compared to low 'compensatory compensators'. However, Corbett et al. (2020) found no differences between high and low camouflagers on Verbal IQ or Performance IQ. The one study using a self-report methodology with adolescents found no relationship between self-reported camouflaging on the CAT-Q and Full-Scale IQ (Hull, Petrides, \& Mandy, 2021), although it should be acknowledged that this study was only powered to detect large effects.

Regarding executive functioning, Livingston, Colvert, et al. (2019) reported that high compensators demonstrated better executive functioning abilities than low compensators. Hull, Petrides and Mandy (2021) found that fewer executive functioning difficulties predicted greater total self-report camouflaging on the CAT-Q.

\section{Is camouflaging related to current age or age at diagnosis?}

Adults. Five studies examined relationships between age and camouflaging in autistic adults. Four of these studies found no relationship between camouflaging and age, or age at diagnosis, using either internal-external discrepancy (Lai et al. 2017) or self-report measures (Cage \& Troxell-Whitman, 2019, Cassidy et al., 2018; Livingston et al. 2020). However, the one self-report study using a validated measure of camouflaging found that age, and age at diagnosis, may be associated with camouflaging 
such that older age suggestively predicted lower total CAT-Q scores while older age at diagnosis suggestively predicted higher total CAT-Q scores (Perry et al., 2021).

Children and Adolescents. A further four articles presented data on age and camouflaging in children and adolescents. No evidence was found to support a relationship between camouflaging or compensation and age in autistic adolescents using either internal-external discrepancy approaches (Livingston, Colvert, et al., 2019) or self-report measures (Hull, Petrides, \& Mandy, 2021; Jorgenson et al., 2020). However, the one study comparing masking across different developmental stages suggested that autistic adolescents (13-19 years) displayed higher parent-reported levels of masking than autistic children (5-12 years; Ormond et al., 2018).

\section{What is the relationship between camouflaging and mental health and wellbeing outcomes?}

Adults. Ten of the identified studies explored associations between camouflaging and well-being and/or mental health in adults using internal-external discrepancy and self-report approaches. Overall, significant evidence from eight of these ten studies supported a relationship between increased selfreported camouflaging and poorer mental health.

Initial studies, employing a variety of self-report methodologies, provided mixed support for an association between camouflaging and mental health. Spontaneously reported camouflaging (in text responses to questions about autism acceptance and mental health) was associated with higher depression, but not anxiety or stress scores (Cage et al., 2018). Self-reported camouflaging on a set of four items predicted suicidality after controlling for a range of additional factors, but it was not associated with a self-reported diagnosis of depression or an anxiety disorder (Cassidy et al., 2018). Camouflaging in more environments or contexts was also associated with increased anxiety and stress, but not depressive symptoms (Cage \& Troxell-Whitman, 2019).

Later studies quantifying both camouflaging and mental health constructs using validated measures have provided more consistent evidence suggesting that greater self-reported camouflaging 
(i.e., higher Total CAT-Q scores) is associated with increased neuroticism (Robinson et al., 2020); increased social anxiety, general anxiety, and depressive symptoms (Hull et al., 2019; Hull, Levy, et al., 2021); greater psychological distress (Beck et al., 2020); and decreased well-being (Hull et al., 2019; although see Perry et al., 2021). However, there was no evidence that the relationship between selfreported camouflaging and mental health outcomes was moderated by gender (Hull, Levy, et al., 2021).

Two small-scale studies employing internal-external discrepancy approaches examined associations between camouflaging and mental health outcomes separately for autistic men and women. Lai et al. (2017) found that higher camouflaging scores were associated with greater depressive symptoms in men but not women, while camouflaging was not associated with anxiety symptoms in either sex/gender. Similarly, Schuck et al. (2019) found no relationship between camouflaging scores and social anxiety symptoms for either sex/gender.

Children and Adolescents. Three studies using internal-external discrepancy and self-report approaches yielded some preliminary evidence supporting an association between camouflaging and poorer mental health in children and adolescents. Two studies examined associations between camouflaging and anxiety in children and adolescents using internal-external discrepancy methods. Livingston, Colvert, et al. (2019) reported that high compensators demonstrated high self-report (but not parent-report) anxiety compared to low compensators. Corbett et al. (2020) found no differences between high and low compensators in terms of self-report trait or state anxiety. However, low compensators demonstrated higher levels of observer-rated anxiety compared to high compensators. The sole study using a self-report approach found that greater self-reported camouflaging was associated with higher levels of anxiety and depression in both autistic and non-autistic adolescents (Bernardin et al., 2020). 


\section{Discussion}

Camouflaging refers to the conscious or unconscious employment of specific behavioural and cognitive strategies used by autistic people to adapt to, or cope within, the predominately non-autistic social world (Cook, Crane, Hull, et al., 2021; Hull et al., 2019; Lai et al., 2017; Lawson, 2020).

Camouflaging may enable autistic people to (consciously or unconsciously) present a non-autistic social style, hide autistic characteristics, and/or minimise the visibility of social difficulties. The current systematic review aimed to critically evaluate existing quantitative camouflaging research to identify consistencies in the current evidence base, as well as gaps that require further research. We identified 29 studies quantifying camouflaging in children/adolescents and adults with autism diagnoses or high levels of autistic traits. Next, we provide an overview of current measurement approaches as well key findings, before discussing limitations in the current literature and providing suggestions for future research.

\section{Research into Camouflaging and Autism: Current Measurement Approaches}

The multiple methods used to measure camouflaging in included studies broadly fell under two different approaches: internal-external discrepancy and self-report approaches. The internal-external discrepancy approach aimed to measure camouflaging by quantifying differences between internal ('true') autistic status and observable behavioural presentation (Lai et al., 2017, 2020). Following this approach, high camouflaging was conceptualised as either fewer social-communication difficulties or more 'typical' social behaviour despite high autistic traits/poor social cognition abilities. Across studies, various self- or parent-report measures of autistic traits and/or performance-based measures of social cognition were used as proxy measures of 'true' autistic status, while an observer rated assessment of autistic behaviour (i.e., ADOS) was typically used as a measure of external behavioural presentation (however, see Parish-Morris et al., 2017; Rynkiewcz et al., 2016; Wood-Downie et al., 2020). Adult studies calculated individual camouflaging scores for participants, while child/adolescent studies 
stratified children/adolescents into camouflaging ability groups and/or described group level differences between boys and girls. Such methods highlight an important issue related to camouflaging and diagnosis: certain autistic individuals show strengths in performance on observer-rated assessments of social communication, relative to performance on measures of social cognition and scores on measures of overall autistic traits.

However, several important criticisms have been raised questioning the underlying assumptions of the internal-external discrepancy approach (e.g., Fombonne, 2020; Pearson \& Rose, 2021; Williams, 2021). First, given the multiple behavioural, cognitive, and sensory domains implicated in autism, performance on a measure of social cognition alone is arguably a poor proxy for 'true' autistic status (Lai et al., 2017). Second, recent evidence suggests that lab-based measures of social cognition may not ordinarily predict observable social behaviour in either autistic or non-autistic people (Morrison et al., 2020; Williams, 2021). Third, given that the ADOS was developed using predominately white, male samples, scores on this measure may reflect, at least in part, the degree to which an individual's behavioural presentation ordinarily deviates from the stereotypically male autistic presentation, rather than the degree to which an individual's behavioural presentation is changed via camouflaging (Pearson \& Rose, 2021). Fourth, the relationship between greater self-report levels of autistic traits and improved performance on measures of social communication may be driven by social insight or reasoning as opposed to camouflaging (Livingston et al., 2020).

In contrast to the internal-external discrepancy approach, self-report approaches measure selfperceived engagement in camouflaging independent of observable behavioural presentation (Hull et al., 2019). For this reason, self-report methodologies could be conceptualised as measuring camouflaging attempts, efforts, or intentions (e.g., Beck et al., 2020; Hull, Petrides, \& Mandy, 2021; Livingston et al., 2020). Operationalisation of camouflaging varied significantly across studies from spontaneous descriptions of camouflaging in response to open-ended questions, to reported time spent camouflaging 
across various settings, to endorsement of specific camouflaging behaviours and strategies. Some promising self-report camouflaging measures are yet to demonstrate reliability and validity, so require further formal testing (Williams, 2021). However, 13 of the 19 self-report studies used the CAT-Q; a camouflaging measure validated in a large sample of autistic and non-autistic adults (Hull et al., 2019; Williams, 2021). In this regard, the CAT-Q showed potential as measure of self-perceived camouflaging, demonstrating sound internal consistency and test-retest reliability and performing generally as expected when tested in relation to gender, autistic traits, and mental health and wellbeing (Hull et al., 2019; although see Fombonne, 2020).

However, it is important to note that camouflaging likely involves both the conscious and unconscious employment of behavioural and cognitive strategies. In this regard, self-report measures are limited in measuring unconscious engagement in camouflaging (Lawson, 2020). Moreover, several behaviours and strategies included on self-report measures appear to overlap with behaviours associated with more established constructs such as social anxiety/safety behaviours, impression management, and passing (Fombonne et al., 2020; Lai et al., 2020; Williams, 2021). Thus, the degree to which camouflaging behaviours and strategies, as measured in current self-report measures, represent a theoretically distinct phenomena, remains unclear.

It is likely that internal-external discrepancy and self-report approaches measure distinct but potentially converging elements of camouflaging (Lai et al., 2020). Self-report methodologies may measure the extent to which individuals consciously employ camouflaging behaviours and strategies, and we label this 'camouflaging intent'. By contrast, internal-external discrepancy methods may capture the extent to which these behaviours and strategies (as well as behaviours and strategies operating outside of conscious awareness) translate into observable social behaviour, and we label this 'camouflaging efficacy'. We note here that, as previously described, camouflaging may not be a desired but rather a necessary coping strategy for autistic people, and so 'efficacy' refers to meeting intended 
aims rather than optimal outcomes. It is important to acknowledge that given the nascent stage of empirical research examining camouflaging, methods for measuring the phenomena are in their infancy. Currently, there is a dearth of research investigating relationships between either internal-external discrepancy or self-report measures of camouflaging and measures of more established, theoretically related constructs (e.g., impression management, social anxiety, passing; Lai et al., 2017, 2020). Similarly, self-report and internal-external discrepancy methods have not been directly compared, to determine the extent to which these show concurrent validity in measuring the same underlying construct (Fombonne, 2020). It is also important to note that, in the current systematic review, we were not able to aggregate data across studies via meta-analytic techniques, owing to differences both between and within measurement approaches.

\section{Research into Camouflaging in Autism: Current Findings}

The literature we reviewed suggests the following three preliminary findings about the nature of autistic camouflaging. First, emerging evidence suggests that adults with higher self-reported autistic traits report greater camouflaging efforts (Brown et al., 2020; Hull et al., 2019; Livingston et al., 2020). Having an autism diagnosis similarly appears to be associated with greater camouflaging efforts, and there is some evidence to suggest this relationship is driven by autistic traits rather than the presence of diagnostic label per se (Livingston et al., 2020). Such findings suggest that regardless of diagnosis, adults with higher self-reported autistic traits feel a greater need to modify their social behaviour via the use of camouflaging strategies. The underlying mechanisms contributing to increased camouflaging amongst those with higher autistic traits are not yet clear. However, preliminary findings from two included studies suggest that experiences of stigma and not feeling accepted play a role (Cage et al., 2018; Perry et al., 2021).

The second key finding from this review is that, across the lifespan, the majority of included studies found that autistic females and girls/women demonstrate higher levels of camouflaging than 
autistic males and boys/men (Cassidy et al., 2018; Corbett et al., 2021; Hull, Lai, et al., 2020;

Jedrzejewskar \& Dewey, 2021; Lai et al., 2017; Ormond et al., 2018; Parish-Morris et al., 2017; Perry et al., 2021; Ratto et al., 2018; Rynkiewcz et al., 2016; Schuck, et al., 2019; Wood-Downie et al., 2020). The remaining included studies found null results and no study found the converse effect of higher camouflaging in males or boys/men. Sex and gender differences were demonstrated using both selfreport and internal-external discrepancy measurement approaches. While no study directly compared camouflaging efforts and observable social behaviours, these findings provide preliminary evidence that compared to autistic males and boys/men, autistic females and girls/women appear to consciously engage in more camouflaging, with more noticeable effects. Thus, the current evidence base appears to support suggestions that camouflaging is more associated with the experiences of autistic females and girls/ women, and may partially explain increased rates of missed or late diagnosis found amongst them (Duvekot et al., 2017; Dworzynski et al., 2012; Head et al., 2014; Kirkovosi et al., 2013; Lai \& BaronCohen, 2015; Lehnhardt et al., 2016; Shattuck et al., 2009; Whitlock et al., 2020). Yet, the consistent documentation of camouflaging in autistic males and boys/men also shows that camouflaging is not specific to females and girls/women (Lai et al., 2017; Hull, Lai, et al., 2020). Indeed, given the effect sizes were often small-to-moderate for sex and gender differences, the real-life camouflaging experiences of these groups may be broadly similar.

Unfortunately, owing to a lack of research involving adequately powered samples of non-binary people, drawing conclusions about differences in camouflaging between binary and non-binary genders was not possible. It is, however, important to acknowledge that one study found non-binary autistic people to engage in similar levels of camouflaging to autistic women (Perry et al., 2021). It should be added that a more nuanced understanding of sex and gender differences in camouflaging is currently lacking, owing in part to included studies largely failing to provide a comprehensive characterisation of participants' gender identity via the description of the multiple components of sex and gender. 
The third key finding was that, for autistic adults, higher self-reported camouflaging appeared to be associated with increased symptoms of mental ill health (Beck et al., 2020; Cage et al., 2018; Cage \& Troxell-Whitman, 2019; Cassidy et al., 2018; Hull et al., 2019, 2021; Lai et al., 2017; Robinson et al., 2020). As such, the current evidence base suggests that autistic individuals who feel a greater need to modify their social behaviours via camouflaging experience more mental health difficulties. At the same time, an association between observable camouflaging efficacy, measured via internal-external discrepancy approaches, and mental health difficulties was not consistently found for either autistic adults or children. Thus, the relationship between camouflaging and mental health difficulties may be more related to an individuals' belief that they need to camouflage their autism rather than their ability to do so. However, to date, no studies have explored interactions between mental health difficulties, camouflaging intention and camouflaging efficacy. Moreover, it is important to note that due to the cross-sectional nature of the current research base, a causal relationship between camouflaging and mental health difficulties cannot be inferred. Nonetheless, any association between psychological distress and camouflaging is of significant concern, given the high rates of co-occurring mental health difficulties found amongst autistic adults (Lever \& Geurst, 2016).

\section{Research into Camouflaging in Autism: Current Limitations}

As is often the case in autism research (e.g., West et al., 2016; Russell et al., 2019), most of the included studies were limited regarding their characterisation of participants. Many studies failed to provide information regarding participants' $I Q$, educational attainment, social economic status, and race/ethnicity. Similarly, as previously mentioned, the description of the multiple components of sex and gender was largely absent in included studies. Given the heterogeneity of the autistic community, adequately described samples are key in determining the generalisability of research findings. Equally, comprehensive descriptions of race/ethnicity, gender identity, sexual orientation, and social economic status are especially necessary in camouflaging research owing to the likely role of marginalisation in the 
development and perseverance of camouflaging (Botha \& Frost, 2020; Lai et al., 2020; Perry et al., 2021).

Notwithstanding, available data suggested that adult participants in camouflaging research were mostly white, university educated females and/or women diagnosed in adulthood with a mean IQ in the "high average" range. By contrast, child and adolescent participants were mostly white males and/or boys diagnosed in childhood with a mean IQ in the "average" range. Current evidence of camouflaging across the lifespan therefore involves samples differing on the key demographics of sex and gender, IQ, and age of diagnosis, which makes it difficult to draw inferences about the progression of camouflaging across different developmental stages. Moreover, given these sample demographics, the current camouflaging evidence base cannot be applied to the autistic community as a whole. Adult-focused research particularly is limited in generalisability regarding males and men, people of non-white ethnic groups or races, those diagnosed in childhood, those with lower educational attainment, and those with intellectual disabilities.

In seeking to design camouflaging research that is more representative of the broader autistic community, it is important to understand why current camouflaging research involves such a specific minority of the larger population of autistic adults. A subset of included studies purposely recruited females or women or those without intellectual disability, to examine specific research questions (Beck et al., 2020; Brown et al., 2020; Lai et al., 2017, 2019; Schuck et al., 2019). However, in the remaining online questionnaire-based studies, individuals largely self-selected to participate by responding to adverts distributed via social media, autism organisations, or research databases. The homogenous nature of these self-selecting samples across studies may indicate that camouflaging is particularly central to the experience of late-diagnosed autistic females and women, a notion that may be supported by the current evidence base. However, the lower rates of males and men in self-report studies may have also resulted in the under identification of camouflaging behaviours and strategies specifically used 
by these groups (Fombonne, 2020). Additionally, the substantial reliance on online questionnaires within camouflaging research likely means members of the autistic community who are less active online or for whom questionnaire-based methods present a barrier to participation (e.g., those with certain intellectual or language difficulties) have been systematically excluded (Hull, Lai, et al., 2020; Lai et al., 2020; Livingston et al., 2020).

\section{Camouflaging in Autism: Future Directions}

\section{Conceptualisation and Measurement of Camouflaging}

Advancement in our understanding of camouflaging is reliant upon valid and reliable camouflaging measures. Given that our current understanding of camouflaging is still emerging, ongoing work is required in refining not only camouflaging measures but also the construct itself (Lai et al., 2020). Current self-report and internal-external discrepancy measurement approaches may capture two distinct but potentially related elements of camouflaging: self-perceived engagement in camouflaging ('camouflaging intent') and observable behavioural presentation ('camouflaging efficacy'). Future research directly comparing self-report and observer rated methods is now required to test this notion and determine the extent to which these elements show concurrent validity in measuring separate aspects of the same underlying construct. Equally, direct comparison of self-report and observer-rated measures is needed to determine the role of conscious awareness in changed social presentation.

It should also be noted however, that across included studies, self-perceived engagement in camouflaging was differentially operationalised as: motivation to engage in camouflaging; specific behaviours and strategies used in camouflaging; and the frequency or pervasiveness of camouflaging in various social contexts. Further research is needed to clearly differentiate these related but separate aspects of camouflaging, and qualitative research may be particularly useful in this regard. Subsequent examination of each of these distinct aspects of camouflaging, related to both self-perceived engagement and observable behaviour change, is required in both autistic and non-autistic samples. 
Specific efforts should be made to include non-autistic samples who similarly experience social challenges (i.e., social anxiety) or stigma, to further the current conceptualisation of camouflaging and help in distinguishing autism specific elements of camouflaging (Lai et al., 2017, 2020).

\section{Longitudinal and Experimental Research}

Although a cross-sectional association between camouflaging and mental health difficulties was identified from the current research base, longitudinal research is now required to investigate the direction of this relationship and causality. Equally, questions regarding causality may be investigated by experimental designs, for example a randomised control trial of an intervention to reduce camouflaging with mental health outcomes as secondary outcomes. Longitudinal research will also be helpful in establishing the developmental trajectory of camouflaging through childhood to adulthood, as well as sex and gender differences in camouflaging across different developmental stages.

\section{Adequately Described, Representative Samples}

Future research should focus on groups currently underrepresented in camouflaging research, including adult males and men, people of non-white ethnic groups and races, those with intellectual disabilities, and adults diagnosed in childhood. Such samples will also facilitate further exploration of the impact of having multiple-minority identities on camouflaging effects (Botha \& Frost, 2020).

Diversification in terms of measures and recruitment practices is likely required to reach such individuals.

\section{Limitation of the current systematic review}

As is the case with any systematic review, our search may not have been exhaustive. Additionally, as authors who have previously published camouflaging research, including research featured in this review, we acknowledge that we are embedded within the camouflaging field and that this may have had an impact on the review. Whilst our familiarity with the topic likely improved our ability to draw conclusions about and identify limitations within the evidence base, it may have 
increased the risk of bias. Finally, the review did not involve participatory design and thus is limited by a lack of autistic input.

\section{Conclusions}

This is the first review to systematically appraise and synthesise the current evidence base pertaining to autistic camouflaging in children and adults of all sexes and genders. Three preliminary conclusions about the nature of autistic camouflaging emerged: (1) adults with more self-reported autistic traits report greater engagement in camouflaging; (2) autistic females and girls/women appear to demonstrate more camouflaging than autistic males and boys/men; and (3) higher self-reported camouflaging is associated with increased mental health difficulties. However, the evidence base was limited regarding participant characterisation and representativeness, suggesting that conclusions cannot be applied to the autistic community as a whole. Given the nascent stage of camouflaging research, future research is required to refine both the construct of camouflaging as well as current measurement approaches (Lai et al., 2020). 


\section{References}

Adams, D., Clark, M., \& Keen, D. (2019). Using self-report to explore the relationship between anxiety and quality of life in children on the autism spectrum. Autism Research, 12(10), 1505-1515. https://doi.org/https://doi.org/10.1002/aur.2155

Allely, C. S. (2019). Understanding and recognising the female phenotype of autism spectrum disorder and the "camouflage" hypothesis: a systematic PRISMA review. Advances in Autism, 5(1), 14-37. https://doi.org/10.1108/aia-09-2018-0036

American Psychiatric Association. (2013). Diagnostic and statistical manual of mental disorders (5 $5^{\text {th }}$ ed.). http://doi.org/10.1176/appi.books.9780890425596

Attwood, T. (2007). The complete guide to Asperger's syndrome. Jessica Kingsly Publishing.

Attwood, T., Garnett, M. S., \& Rynkiewicz, A. (2011). Questionnaire for Autism Spectrum Conditions (Q-ASC) [Measurement instrument].

Bargiela, S., Steward, R., \& Mandy, W. (2016). The Experiences of Late-diagnosed Women with Autism Spectrum Conditions: An Investigation of the Female Autism Phenotype. Journal of Autism and Developmental Disorders, 46(10), 3281-3294. https://doi.org/10.1007/s10803-016-2872-8

Beck, J. S., Lundwall, R. A., Gabrielsen, T., Cox, J. C., \& South, M. (2020). Looking good but feeling bad: "Camouflaging" behaviors and mental health in women with autistic traits. Autism, 24(4), 809821. https://doi.org/https://doi.org/10.1177/1362361320912147*

Bernardin, C. J., Lewis, T., Bell, D., \& Kanne, S. (2021). Associations between social camouflaging and internalizing symptoms in autistic and non-autistic adolescents. Autism. https://doi.org/10.1177/1362361321997284*

Botha, M., \& Frost, D. M. (2020). Extending the minority stress model to understand mental health problems experienced by the autistic population. Society and Mental Health, 10(1), 20-34. https://doi.org/10.1177/2156869318804297 
Bottema-Beutel, K., Kapp, S., Lester, J., Sasson, N. J., \& Hand, B. (2021). Avoiding Ableist Language:

Suggestions for Autism Researchers. Autism in Adulthood, 3(1), 18-29.

https://doi.org/10.1089/aut.2020.0014

Brown, C., Attwood, T., Garnett, M., Stokes, M. (2020). Am I autistic? Utility of the girls questionnaire for autism spectrum condition as an autism assessment in adult women. Autism in Adulthood, 2(3), 216-226. https://doi.org/10.1089/aut.2019.0054*

Cage, E., \& Troxell-Whitman, Z. (2019). Understanding the reasons, contexts and costs of camouflaging for autistic adults. Journal of Autism \& Developmental Disorders, 49(5), 1899-1911. https://doi.org/https://doi.org/10.1007/s10803-018-03878-x *

Cage, E., \& Troxell-Whitman, Z. (2020). Understanding the relationships between autistic identity, disclosure, and camouflaging. Autism in Adulthood, 2(4), 334-338. https://doi.org/10.1089/aut.2020.0016 *

Cage, E., Di Monaco, J., \& Newell, V. (2018). Experiences of autism acceptance and mental health in autistic adults. Journal of Autism \& Developmental Disorders, 48(2), 473-484. https://doi.org/https://doi.org/10.1007/s10803-017-3342-7 *

Cassidy, S., Bradley, L., Shaw, R., \& Baron-Cohen, S. (2018). Risk markers for suicidality in autistic adults. Molecular Autism, 9, 42. https://doi.org/https://doi.org/10.1186/s13229-018-0226-4 *

Charman, T., Jones, C. R., Pickles, A., Simonoff, E., Baird, G., \& Happé, F. (2011). Defining the cognitive phenotype of autism. Brain research, 1380, 10-21. https://doi.org/10.1016/j.brainres.2010.10.075

Cook, J., Crane, L., Bourne, L., Hull, L., \& Mandy, W. (2021). Camouflaging in an everyday social context: An interpersonal recall study. Autism. https://doi.org/10.1177/1362361321992641 *

Corbett, B. A., Schwartzman, J. M., Libsack, E. J., Muscatello, R. A., Lerner, M. D., Simmons, G. L., \& White, S. W. Camouflaging in autism: Examining sex-based and compensatory models in social 
cognition and communication. Autism Research, 14, 127-142.

https://doi.org/https://doi.org/10.1002/aur.2440 *

Cridland, E. K., Jones, S. C., Caputi, P., \& Magee, C. A. (2014). Being a girl in a boys' world: investigating the experiences of girls with autism spectrum disorders during adolescence. Journal of Autism Developmental Disorders, 44(6), 1261-1274. https://doi.org/10.1007/s10803-013-1985-6

Dean, M., Harwood, R., \& Kasari, C. (2017). The art of camouflage: Gender differences in the social behaviors of girls and boys with autism spectrum disorder. Autism, 21(6), 678-689. https://doi.org/https://dx.doi.org/10.1177/13623...

Duvekot, J., van der Ende, J., Verhulst, F. C., Slappendel, G., van Daalen, E., Maras, A., \& Greaves-Lord, K. (2017). Factors influencing the probability of a diagnosis of autism spectrum disorder in girls versus boys. Autism, 21(6), 646-658. https://doi.org/10.1177/1362361316672178

Dworzynski, K., Ronald, A., Bolton, P., \& Happé, F. (2012, 2012/08/01/). How different are girls and boys above and below the diagnostic threshold for autism spectrum disorders? Journal of the American Academy of Child \& Adolescent Psychiatry, 51(8), 788-797. https://doi.org/https://doi.org/10.1016/j.jaac.2012.05.018

Fombonne, E. (2020). Camouflage and autism. Journal of Child Psychology \& Psychiatry \& Allied Disciplines, 61(7), 735-738. https://doi.org/https://doi.org/10.1111/jcpp.13296

Gernsbacher, M. A. (2017). Editorial perspective: the use of person-first language in scholarly writing may accentuate stigma. Journal of Child Psychology and Psychiatry, 58(7), 859-861. https://doi.org/https://doi.org/10.1111/jcpp.12706

Goffman, E. (1959). The presentation of self in everyday life. Garden City.

Gould, J., \& Ashton-Smith, J. (2011). Missed diagnosis or misdiagnosis? Girls and women on the autism spectrum. Good Autism Practice (GAP), 12(1), 34-41. 
Halsall, J., Clarke, C., \& Crane, L. (2021). "Camouflaging" by adolescent autistic girls who attend both mainstream and specialist resource classes: Perspectives of girls, their mothers and their educators. Autism, 13623613211012819. https://doi.org/10.1177/13623613211012819

Head, A. M., McGillivray, J. A., \& Stokes, M. A. (2014). Gender differences in emotionality and sociability in children with autism spectrum disorders. Molecular Autism, 5(1), 19. https://doi.org/10.1186/2040-2392-5-19

Herbison, P., Hay-Smith, J., \& Gillespie, W. J. (2006). Adjustment of meta-analyses on the basis of quality scores should be abandoned. Journal of Clinical Epidemiology, 59(12), 1249-e1. https://doi.org/10.1016/j.jclinepi.2006.03.008

Holliday Willey, L. (1999). Pretending to be normal. Jessica Kingsley Publishers.

Hong, Q. N., Fàbregues, S., Bartlett, G., Boardman, F., Cargo, M., Dagenais, P., Gagnon, M.-P., Griffiths, F., Nicolau, B., O'Cathain, A., Rousseau, M.-C., Vedel, I., \& Pluye, P. (2018). The Mixed Methods Appraisal Tool (MMAT) version 2018 for information professionals and researchers. Education for Information, 34, 285-291. https://doi.org/https://doi.og/10.3233/EFI-180221

Hull, L., Lai, M. C., Baron-Cohen, S., Allison, C., Smith, P., Petrides, K. V., \& Mandy, W. (2020). Gender differences in self-reported camouflaging in autistic and non-autistic adults. Autism, 24(2), 352363. https://doi.org/https://doi.org/10.1002/aur.2407 *

Hull, L., Levy, L., Lai, M. C., Petrides, K. V., Baron-Cohen, S., Allison, C., Smith, P., \& Mandy, W. (2021). Is social camouflaging associated with anxiety and depression in autistic adults? Molecular Autism, 12(1), Article 13. https://doi.org/10.1186/s13229-021-00421-1 *

Hull, L., Mandy, W., Lai, M. C., Baron-Cohen, S., Allison, C., Smith, P., \& Petrides, K. V. (2019).

Development and validation of the camouflaging autistic traits questionnaire (CAT-Q). Journal of Autism \& Developmental Disorders, 49(3), 819-833.

https://doi.org/https://doi.org/10.1007/s10803-018-3792-6 * 
Hull, L., Petrides, K. V., \& Mandy, W. (2020). The female autism phenotype and camouflaging: a narrative review. Review Journal of Autism and Developmental Disorders. https://doi.org/10.1007/s40489-020-00197-9

Hull, L., Petrides, K. V., \& Mandy, W. (2021). Cognitive predictors of self-reported camouflaging in autistic adolescents. Autism Research, 14(3), 523-532. https://doi.org/https://doi.org/10.1002/aur.2407 *

Hull, L., Petrides, K. V., Allison, C., Smith, P., Baron-Cohen, S., Lai, M. C., \& Mandy, W. (2017). "Putting on my best normal": Social camouflaging in adults with autism spectrum conditions. Journal of Autism \& Developmental Disorders, 47(8), 2519-2534. https://doi.org/https://doi.org/10.1007/s10803-017-3166-5 *

Jedrzejewska, A., \& Dewey, J. (2021). Camouflaging in autistic and non-autistic adolescents in the modern context of social media. Journal of Autism and Developmental Disorders. https://doi.org/10.1007/s10803-021-04953-6 *

Jorgenson, C., Lewis, T., Rose, C., \& Kanne, S. (2020). Social camouflaging in autistic and neurotypical adolescents: a pilot study of differences by sex and diagnosis. Journal of Autism \& Developmental Disorders, 08, 08. https://doi.org/10.1007/s10803-020-04491-7 *

Keen, D., Webster, A., \& Ridley, G. (2016). How well are children with autism spectrum disorder doing academically at school? An overview of the literature. Autism, 20(3), 276-294. https://doi.org/10.1177/1362361315580962

Kenny, L., Hattersley, C., Molins, B., Buckley, C., Povey, C., \& Pellicano, E. (2016). Which terms should be used to describe autism? Perspectives from the UK autism community. Autism, 20(4), 442-462. https://doi.org/10.1177/1362361315588200 
Kirkovski, M., Enticott, P. G., \& Fitzgerald, P. B. (2013). A review of the role of female gender in autism spectrum disorders. Journal Autism and Development Disorders, 43(11), 2584-2603. https://doi.org/10.1007/s10803-013-1811-1

Kopp, S., \& Gillberg, C. (1992). Girls with social deficits and learning problems: Autism, atypical Asperger syndrome or a variant of these conditions. European Child \& Adolescent Psychiatry, 1(2), 89-99. https://doi.org/10.1007/BF02091791

Kreiser, N. L., \& White, S. W. (2014). ASD in females: are we overstating the gender difference in diagnosis? Clinical Child and Family Psycholical Review, 17(1), 67-84. https://doi.org/10.1007/s10567-013-0148-9

Lai, M. C., \& Baron-Cohen, S. (2015). Identifying the lost generation of adults with autism spectrum conditions. The Lancet. Psychiatry, 2(11), 1013-1027. https://doi.org/https://doi.org/10.1016/S2215-0366(15)00277-1

Lai, M. C., Lombardo, M. V., Chakrabarti, B., Ruigrok, A. N., Bullmore, E. T., Suckling, J., Auyeung, B., Happe, F., Szatmari, P., Baron-Cohen, S., \& Consortium, M. A. (2019). Neural self-representation in autistic women and association with 'compensatory camouflaging'. Autism, 23(5), 1210-1223. https://doi.org/https://doi.org/10.1177/1362361318807159 *

Lai, M. C., Lombardo, M. V., Ruigrok, A. N., Chakrabarti, B., Auyeung, B., Szatmari, P., Happe, F., BaronCohen, S., \& Consortium, M. A. (2017). Quantifying and exploring camouflaging in men and women with autism. Autism, 21(6), 690-702. https://doi.org/https://doi.org/10.1177/1362361316671012 *

Lai, M.-C., Hull, L., Mandy, W., Chakrabarti, B., Nordahl, C. W., Lombardo, M. V., Ameis, S. H., Szatmari, P., Baron-Cohen, S., Happé, F., \& Livingston, L. A. (2020). Commentary: 'Camouflaging' in autistic people - reflection on Fombonne (2020). Journal of Child Psychology and Psychiatry. https://doi.org/https://doi.org/10.1111/jcpp.13344 
Lai, M.-C., Lombardo, M. V., Pasco, G., Ruigrok, A. N. V., Wheelwright, S. J., Sadek, S. A., Chakrabarti, B., Consortium, M. A., \& Baron-Cohen, S. (2011). A behavioral comparison of male and female adults with high functioning autism spectrum conditions. PLoS One, 6(6), e20835. https://doi.org/https://10.1371/journal.pone.0020835

Lawson, W. B. (2020). Adaptive morphing and coping with social threat in autism: an autistic perspective. Journal of Intellectual Disability - Diagnosis and Treatment, 8(3), 519-526. https://doi.org/10.6000/2292-2598.2020.08.03.29

Leary, M. (1995). Self-presentation: Impression management and interpersonal behaviour. Brown and Benchmark.

Lehnhardt, F. G., Falter, C. M., Gawronski, A., Pfeiffer, K., Tepest, R., Franklin, J., \& Vogeley, K. (2016). Sex-related cognitive profile in autism spectrum disorders diagnosed late in life: implications for the female autistic phenotype. Journal of Autism and Developmental Disorders, 46(1), 139-154. https://doi.org/10.1007/s10803-015-2558-7

Lever, A. G., \& Geurts, H. M. (2016). Psychiatric co-occurring symptoms and disorders in young, middleaged, and older adults with autism spectrum disorder. Journal of Autism and Developmental Disorders, 46(6), 1916-1930. https://doi.org/10.1007/s10803-016-2722-8

Livingston, L. A., \& Happe, F. (2017). Conceptualising compensation in neurodevelopmental disorders: Reflections from autism spectrum disorder. Neuroscience \& Biobehavioral Reviews, 80, 729-742. https://doi.org/https://doi.org/10.1016/j.neubiorev.2017.06.005

Livingston, L. A., Colvert, E., Social Relationships Study, T., Bolton, P., \& Happe, F. (2019). Good social skills despite poor theory of mind: exploring compensation in autism spectrum disorder. Journal of Child Psychology \& Psychiatry \& Allied Disciplines, 60(1), 102-110. https://doi.org/https://doi.org/10.1111/jcpp.12886 * 
Livingston, L. A., Shah, P., \& Happe, F. (2019). Compensatory strategies below the behavioural surface in autism: a qualitative study. The Lancet. Psychiatry, 6(9), 766-777. https://doi.org/https://doi.org/10.1016/S2215-0366(19)30224-X *

Livingston, L. A., Shah, P., Milner, V., \& Happe, F. (2020). Quantifying compensatory strategies in adults with and without diagnosed autism. Molecular Autism, 11(1), 15. https://doi.org/https://doi.org/10.1186/s13229-019-0308-y *

Lounds Taylor, J., Henninger, N. A., \& Mailick, M. R. (2015). Longitudinal patterns of employment and postsecondary education for adults with autism and average-range IQ. Autism, 19(7), 785-793. https://doi.org/10.1177/1362361315585643

Mandy, W. (2019). Social camouflaging in autism: Is it time to lose the mask? Autism, 23(8), 1879-1881. https://doi.org/https://doi.org/10.1177/1362361319878559

Morrison, K. E., DeBrabander, K. M., Jones, D. R., Ackerman, R. A., \& Sasson, N. J. (2020). Social cognition, social skill, and social motivation minimally predict social interaction outcomes for autistic and non-autistic adults. Frontiers in Psychology, 11(3282). https://doi.org/10.3389/fpsyg.2020.591100

Moss, P., Howlin, P., Savage, S., Bolton, P., \& Rutter, M. (2015). Self and informant reports of mental health difficulties among adults with autism findings from a long-term follow-up study. Autism, 19(7), 832-841. https://doi.org/10.1177/1362361315585916

Ormond, S., Brownlow, C., Garnett, M. S., Rynkiewicz, A., \& Attwood, T. (2018). Profiling Autism symptomatology: an exploration of the Q-ASC parental report scale in capturing sex differences in autism. Journal of Autism and Developmental Disorders, 48(2), 389-403. https://doi.org/10.1007/s10803-017-3324-9 *

Ouzzani, M., Hammady, H., Fedorowicz, Z., \& Elmagarmid, A. (2016). Rayyan-a web and mobile app for systematic reviews. Systematic Reviews, 5(1), 210. https://doi.org/10.1186/s13643-016-0384-4 
Page, M. J., McKenzie, J. E., Bossuyt, P. M., Boutron, I., Hoffmann, T. C., Mulrow, C. D., Shamseer, L., Tetzlaff, J. M., \& Moher, D. (2021). Updating guidance for reporting systematic reviews: development of the PRISMA 2020 statement. Journal of Clinical Epidemiology, 134, 103-112. https://doi.org/https://doi.org/10.1016/j.jclinepi.2021.02.003

Parish-Morris, J., Liberman, M. Y., Cieri, C., Herrington, J. D., Yerys, B. E., Bateman, L., Donaher, J., Ferguson, E., Pandey, J., \& Schultz, R. T. (2017). Linguistic camouflage in girls with autism spectrum disorder. Molecular Autism, 8, 48. https://doi.org/https://doi.org/10.1186/s13229017-0164-6 *

Pearson, A., \& Rose, K. (2021). A conceptual analysis of autistic masking: Understanding the narrative of stigma and the illusion of choice. Autism in Adulthood, 3(1), 52-60. https://doi.org/10.1089/aut.2020.0043

Perry, E., Mandy, W., Hull, L., \& Cage, E. (2021). Understanding camouflaging as a response to autismrelated stigma: a social identity theory approach. Journal of Autism and Developmental Disorders. https://doi.org/10.1007/s10803-021-04987-w *

Pledger, L. M. (1992). Development of self-monitoring behavior from early to late adolescence. Adolescence, 27(106), 329-338

Ratto, A. B., Kenworthy, L., Yerys, B. E., Bascom, J., Wieckowski, A. T., White, S. W., Wallace, G. L., Pugliese, C., Schultz, R. T., Ollendick, T. H., Scarpa, A., Seese, S., Register-Brown, K., Martin, A., \& Anthony, L. G. (2018, 2018/05/01). What about the girls? Sex-based differences in autistic traits and adaptive skills. Journal of Autism and Developmental Disorders, 48(5), 1698-1711. https://doi.org/10.1007/s10803-017-3413-9*

Robinson, E. B., St Pourcain, B., Anttila, V., Kosmicki, J. A., Bulik-Sullivan, B., Grove, J., Maller, J., Samocha, K. E., Sanders, S. J., Ripke, S., Martin, J., Hollegaard, M. V., Werge, T., Hougaard, D. M., Neale, B. M., Evans, D. M., Skuse, D., Mortensen, P. B., Børglum, A. D., Ronald, A., Smith, G. D., \& 
Daly, M. J. (2016). Genetic risk for autism spectrum disorders and neuropsychiatric variation in the general population. Nature Genetics, 48(5), 552-555.

https://doi.org/http://doi.org/10.1038/ng.3529

Robinson, E., Hull, L., \& Petrides, K. (2020). Big Five model and trait emotional intelligence in camouflaging behaviours in autism. Personality and Individual Differences 152. https://doi.org/https://doi.org/10.1016/j.paid.2019.109565*

Russell, G., Mandy, W., Elliott, D., White, R., Pittwood, T., \& Ford, T. (2019). Selection bias on intellectual ability in autism research: A cross-sectional review and meta-analysis. Molecular Autism, 10(1), 1-10. https://doi.org/10.1186/s13229-019-0260-x

Rynkiewicz, A., Schuller, B., Marchi, E., Piana, S., Camurri, A., Lassalle, A., \& Baron-Cohen, S. (2016). An investigation of the 'female camouflage effect' in autism using a computerized ADOS-2 and a test of sex/gender differences. Molecular Autism, 7, 10. https://doi.org/https://doi.org/10.1186/s13229-016-0073-0 *

Sarrett, J. C. (2016). Biocertification and neurodiversity: the role and implications of self-diagnosis in autistic communities. Neuroethics, 9(1), 23-36. https://doi.org/10.1007/s12152-016-9247-x

Schuck, R. K., Flores, R. E., \& Fung, L. K. (2019). Brief report: Sex/gender differences in symptomology and camouflaging in adults with autism spectrum disorder. Journal of Autism \& Developmental Disorders, 49(6), 2597-2604. https://doi.org/https://doi.org/10.1007/s10803-019-03998-y *

Shattuck, P. T., Durkin, M., Maenner, M., Newschaffer, C., Mandell, D. S., Wiggins, L., Lee, L.-C., Rice, C., Giarelli, E., Kirby, R., Baio, J., Pinto-Martin, J., \& Cuniff, C. (2009). Timing of identification among children with an autism spectrum disorder: Findings from a population-based surveillance study. Journal of the American Academy of Child \& Adolescent Psychiatry, 48(5), 474-483. https://doi.org/https://doi.org/10.1097/CHI.0b013e31819b3848 
Simonoff, E., Pickles, A., Charman, T., Chandler, S., Loucas, T., \& Baird, G. (2008). Psychiatric disorders in children with autism spectrum disorders: Prevalence, comorbidity, and associated factors in a population-derived sample. Journal of the American Academy of Child \& Adolescent Psychiatry, 47(8), 921-929. https://doi.org/https://doi.org/10.1097/CHI.0b013e318179964f

Tierney, S., Burns, J., \& Kilbey, E. (2016). Looking behind the mask: Social coping strategies of girls on the autistic spectrum. Research in Autism Spectrum Disorders, 23, 73-83. https://doi.org/https://doi.org/10.1016/j.rasd.2015.11.013

Tubio-Fungueirino, M., Cruz, S., Sampaio, A., Carracedo, A., \& Fernandez-Prieto, M. (2021). Social camouflaging in females with autism spectrum disorder: a systematic review. Journal of Autism \& Developmental Disorders, 14, 14. https://doi.org/https://doi.org/10.1007/s10803-020-04695$\mathrm{X}$

West, E. A., Travers, J. C., Kemper, T. D., Liberty, L. M., Cote, D. L., McCollow, M. M., \& Stansberry Brusnahan, L. L. (2016). Racial and ethnic diversity of participants in research supporting evidence-based practices for learners with autism spectrum disorder. The Journal of Special Education, 50(3), 151-163. https://doi.org/10.1177/0022466916632495

Whitlock, A., Fulton, K., Lai, M. C., Pellicano, E., \& Mandy, W. (2020). Recognition of girls on the autism spectrum by primary school educators: an experimental study. Autism Research, 13(8), 13581372. https://doi.org/10.1002/aur.2316

Williams, Z. J. (2021). Commentary: The construct validity of 'camouflaging' in autism: psychometric considerations and recommendations for future research - reflection on Lai et al., (2020). Journal of Child Psychology and Psychiatry. https://doi.org/https://doi.org/10.1111/jcpp.13468

Wood-Downie, H., Wong, B., Kovshoff, H., Mandy, W., Hull, L., \& Hadwin, J. A. (2020). Sex/gender differences in camouflaging in children and adolescents with autism. Journal of Autism \& Developmental Disorders, 20, 20. https://doi.org/10.1007/s10803-020-04615-z * 
Note. ${ }^{*}=$ included in systematic review 


\section{Table 1}

Study Inclusion and Exclusion Criteria.

\begin{tabular}{lll}
\hline & Inclusion Criteria & Exclusion Criteria \\
\hline Design & $\begin{array}{l}\text { Reported quantitative data } \\
\text { measuring camouflaging (i.e. } \\
\text { numerical data quantifying } \\
\text { camouflaging strategies or } \\
\text { behaviour within an individual } \\
\text { or group). }\end{array}$ & $\begin{array}{l}\text { Reported purely qualitative } \\
\text { data. }\end{array}$ \\
& $\begin{array}{l}\text { Participants were autistic } \\
\text { individuals (either those with a } \\
\text { clinical diagnosis of autism or } \\
\text { those who self-identified }{ }^{4} \text { as } \\
\text { autistic) or individuals with high }\end{array}$ & $\begin{array}{l}\text { Studies only involving general } \\
\text { population samples. }\end{array}$ \\
& $\begin{array}{l}\text { levels of autistic traits (as } \\
\text { defined by study authors). }\end{array}$ & \\
\hline Publication & Studies published (or accepted & Articles not reporting peer- \\
& for publication) in peer & reviewed, original empirical \\
& reviewed academic journals. & findings such as opinion pieces, \\
& & conceptual pieces, thesis, and \\
& & \\
\hline Language & Written in English. & \\
\hline
\end{tabular}

${ }^{4}$ Some members of real-world autistic communities are self-identified or self-diagnosed (Sarrett, 2016). Such autistic individuals who recognise autistic traits within themselves but do not meet or are yet to meet criteria for a clinical diagnosis, may be particularly adept at camouflaging their autistic traits (e.g., Lai et al., 2017; Livingston, Shah, et al., 2019). 
Figure 1

PRISMA Flow Diagram Showing Study Selection

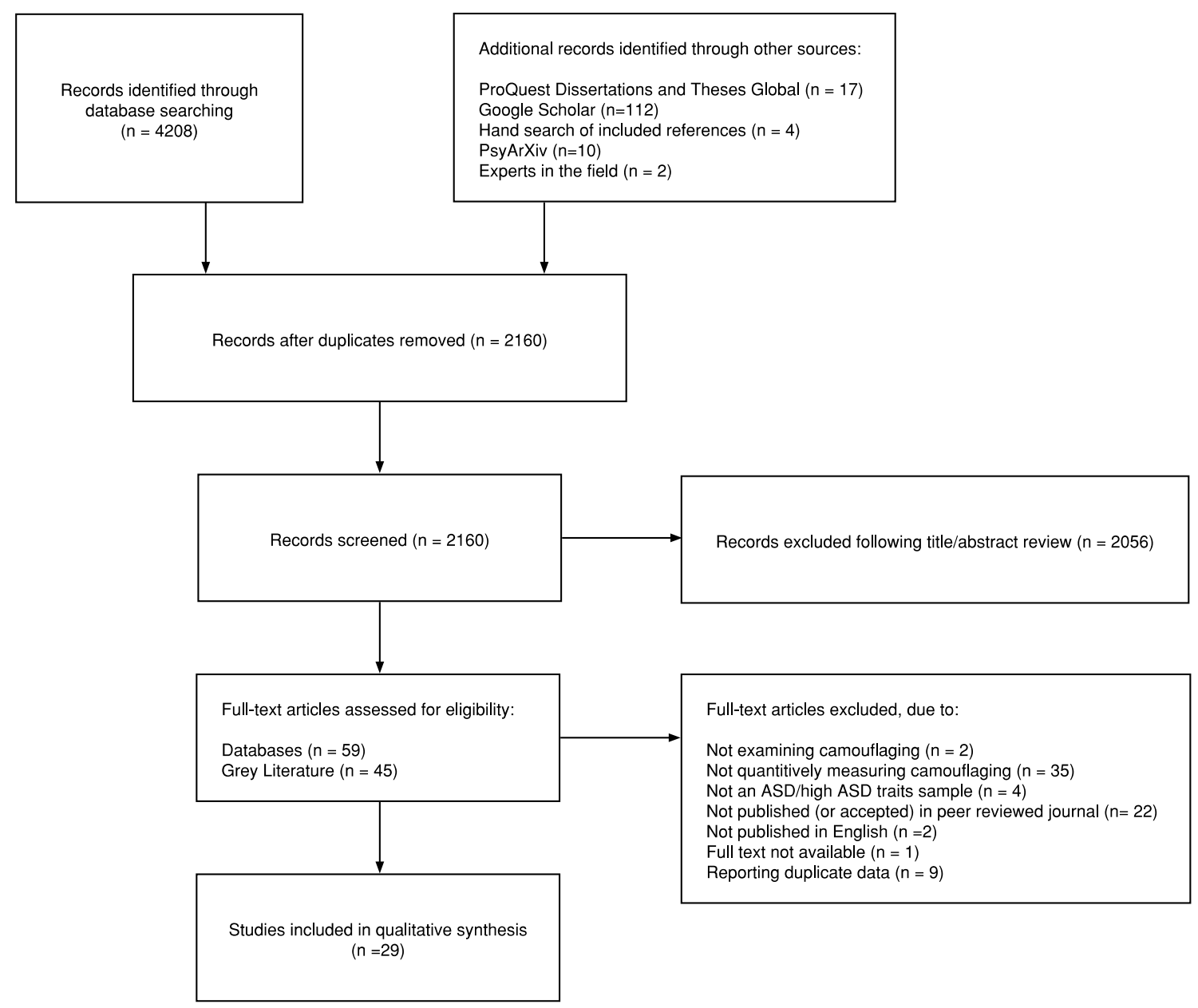




\section{Table 2}

Aggregated Participant Characteristics

\begin{tabular}{|c|c|c|c|c|c|c|c|c|}
\hline & $\begin{array}{c}\% \\
\text { Gender }\end{array}$ & $\begin{array}{l}\text { Mean } \\
\text { age }\end{array}$ & $\begin{array}{c}\text { Mean } \\
\text { age of } \\
\text { diagnosis }\end{array}$ & $\begin{array}{l}\text { Mean } \\
\text { FSIQ }\end{array}$ & $\begin{array}{c}\text { \% Clinical } \\
\text { autism } \\
\text { diagnosis }\end{array}$ & $\begin{array}{l}\text { \% Race/ethnic } \\
\text { group }^{\mathrm{a}}\end{array}$ & $\%$ Educational attainment & $\begin{array}{c}\text { \% Co-morbid mental health } \\
\text { diagnosis }^{\mathrm{a}}\end{array}$ \\
\hline $\begin{array}{l}\mathrm{N} \text { adult studies } \\
\text { used in calculations }\end{array}$ & 14 & 13 & 7 & 4 & 14 & 8 & 6 & 5 \\
\hline $\begin{array}{l}\text { Adult studies }(n= \\
18)\end{array}$ & $\begin{array}{l}60.1 \mathrm{~F} ; \\
29.0 \mathrm{M} ; \\
8.3 \mathrm{O} ; \\
2.6 \\
\text { n.r. }\end{array}$ & 36.47 & 32.98 & 112.35 & 95.9 & $\begin{array}{l}86.1 \text { White; } 4.1 \\
\text { Mixed; } 1.4 \text { Asian; } 0.5 \\
\text { Hispanic/Latino/a; } \\
0.2 \text { Black; } 1.2 \text { Other; } \\
6.9 \text { n.r. }\end{array}$ & $\begin{array}{l}\text { 4.9 No qualifications; } 25.1 \\
\text { High school or equivalent; } \\
30.0 \text { Undergraduate } \\
\text { degree; } 24.0 \text { Post- } \\
\text { graduate degree; } 12.3 \\
\text { Other; } 3.7 \text { n.r. }\end{array}$ & $\begin{array}{l}\text { 53.1 Depression; } 54.8 \\
\text { General anxiety; } 6.5 \text { Social } \\
\text { anxiety; } 0.4 \text { Specific phobia; } \\
\text { 11.0 OCD; } 5.5 \text { PTSD; } 4.3 \\
\text { Bipolar disorder; } 3.7 \\
\text { Personality disorder; } 0.9 \\
\text { Schizophrenia; } 2.4 \text { Eating } \\
\text { disorder }\end{array}$ \\
\hline $\begin{array}{l}\mathrm{N} \text { child studies used } \\
\text { in calculations }\end{array}$ & 10 & 8 & & 7 & 10 & 2 & & 1 \\
\hline $\begin{array}{l}\text { Child studies }(n= \\
11)\end{array}$ & $\begin{array}{l}36.9 \mathrm{~F} ; \\
62.9 \mathrm{M} ; \\
0.3 \mathrm{O}\end{array}$ & 11.90 & & 99.93 & 94.7 & $\begin{array}{l}\text { 75.8 White; } 5.5 \\
\text { Black; } 4.1 \\
\text { Hispanic/Latino/a; } \\
\text { 3.4 Asian; } 7.8 \\
\text { Other/Unknown; } 3.4 \\
\text { n.r }\end{array}$ & & 40.7 Co-morbid diagnosis \\
\hline
\end{tabular}

Note. $\mathrm{F}$ = female; $\mathrm{M}=$ male; $\mathrm{O}=$ other (study authors reported a range of genders included as 'other' such as non-binary, genderfluid, transgender male and transgender female); n.r. = not reported. Percentage may not sum to 100 due to rounding.

a Percentages will not sum to 100 due to categories not being mutually exclusive. 


\section{Table 3}

Overview of Internal-External Discrepancy Measurement Methods

\begin{tabular}{|c|c|c|c|c|c|}
\hline $\begin{array}{l}\text { Author } \\
\text { (Year) }\end{array}$ & $\begin{array}{l}\text { Operationalisation of } \\
\text { camouflaging }\end{array}$ & $\begin{array}{l}\text { Autistic } \\
\text { traits/social } \\
\text { communication } \\
\text { skill measure }\end{array}$ & $\begin{array}{l}\text { Social cognitive } \\
\text { ability measure; } \\
\text { Social cognitive } \\
\text { ability }\end{array}$ & $\begin{array}{l}\text { Measure of } \\
\text { behavioural } \\
\text { presentation }\end{array}$ & Type of outcome \\
\hline \multicolumn{6}{|l|}{ Adult Studies } \\
\hline $\begin{array}{l}\text { Lai et al. } \\
(2017)\end{array}$ & $\begin{array}{l}\text { Discrepancy between self- } \\
\text { reported autistic } \\
\text { traits/performance based socio- } \\
\text { cognitive ability and observer } \\
\text { rated social behaviour }\end{array}$ & $\mathrm{AQ}$ & REMT; TOM & ADOS & $\begin{array}{l}\text { Individual camouflaging } \\
\text { scores }\end{array}$ \\
\hline $\begin{array}{l}\text { Lai et al. } \\
\text { (2019) }\end{array}$ & $\begin{array}{l}\text { Discrepancy between self- } \\
\text { reported autistic } \\
\text { traits/performance based socio- } \\
\text { cognitive ability and observer } \\
\text { rated social behaviour }\end{array}$ & $\mathrm{AQ}$ & REMT; TOM & ADOS & $\begin{array}{l}\text { Individual camouflaging } \\
\text { scores }\end{array}$ \\
\hline $\begin{array}{l}\text { Schuck et al. } \\
\text { (2019) }\end{array}$ & $\begin{array}{l}\text { Discrepancy between self- } \\
\text { reported autistic traits and } \\
\text { observer rated social behaviour }\end{array}$ & $\mathrm{AQ}$ & - & ADOS & $\begin{array}{l}\text { Individual camouflaging } \\
\text { scores }\end{array}$ \\
\hline \multicolumn{6}{|c|}{ Child/Adolescent Studies } \\
\hline $\begin{array}{l}\text { Rynkiewcz et } \\
\text { al. (2016) }\end{array}$ & $\begin{array}{l}\text { Discrepancy between parent- } \\
\text { reported autistic traits/social } \\
\text { communication skills and } \\
\text { "Gesture Index" }\end{array}$ & $\mathrm{AQ}, \mathrm{SCQ}$ & - & $\begin{array}{l}\text { Computerized data } \\
\text { on gestures } \\
\text { occurring during two } \\
\text { sections of the } \\
\text { ADOS-2 }\end{array}$ & Group level differences \\
\hline $\begin{array}{l}\text { Parish- } \\
\text { Morris et al. } \\
(2017)\end{array}$ & $\begin{array}{l}\text { Discrepancy between parent- } \\
\text { reported autistic traits/social } \\
\text { communication skills and } \\
\text { pragmatic language markers }\end{array}$ & SCQ, Vineland-II & - & $\begin{array}{l}\text { Pragmatic language } \\
\text { markers occurring } \\
\text { during a section of } \\
\text { the ADOS-2 }\end{array}$ & Group level differences \\
\hline
\end{tabular}




\begin{tabular}{|c|c|c|c|c|c|}
\hline $\begin{array}{l}\text { Ratto et al. } \\
\text { (2018) }\end{array}$ & $\begin{array}{l}\text { Discrepancy between parent } \\
\text { reported autistic traits/social } \\
\text { communication skills and } \\
\text { performance on gold-standard } \\
\text { diagnostic measures }\end{array}$ & $\begin{array}{l}\text { ADI-R, SRS, SRS-2, } \\
\text { Vineland-II }\end{array}$ & - & ADOS/ADOS-2 & Group level differences \\
\hline $\begin{array}{l}\text { Livingston, } \\
\text { Colvert, et } \\
\text { al. (2019) }\end{array}$ & $\begin{array}{l}\text { Discrepancy between } \\
\text { performance based socio- } \\
\text { cognitive ability and observer } \\
\text { rated social behaviour }\end{array}$ & - & $\begin{array}{l}\text { Frith-Happé } \\
\text { Animations; } \\
\text { ToM }\end{array}$ & ADOS & $\begin{array}{l}\text { Four compensation } \\
\text { ability groups (low } \\
\text { compensators, high } \\
\text { compensators, deep } \\
\text { compensators, and } \\
\text { unknown) }\end{array}$ \\
\hline $\begin{array}{l}\text { Corbett et al. } \\
(2020)\end{array}$ & $\begin{array}{l}\text { Discrepancy between } \\
\text { performance based socio- } \\
\text { cognitive ability and observer } \\
\text { rated social behaviour }\end{array}$ & - & $\begin{array}{l}\text { NEPSY-II (theory } \\
\text { of mind } \\
\text { subscale); ToM }\end{array}$ & ADOS-2 & $\begin{array}{l}\text { Four compensation ability } \\
\text { groups (low } \\
\text { compensation, high } \\
\text { compensation, deep } \\
\text { compensation, and } \\
\text { unknown) }\end{array}$ \\
\hline $\begin{array}{l}\text { Wood- } \\
\text { Downie et al. } \\
(2020)\end{array}$ & $\begin{array}{l}\text { Discrepancy between parent } \\
\text { reported autistic } \\
\text { traits/performance based socio- } \\
\text { cognitive ability and } \\
\text { performance-based social } \\
\text { reciprocity }\end{array}$ & $\mathrm{SCDC}$ & REMT; ToM & IDT & $\begin{array}{l}\text { 1. Two compensatory } \\
\text { camouflaging ability } \\
\text { groups (low } \\
\text { compensation and high } \\
\text { compensation) } \\
\text { 2. Group level differences }\end{array}$ \\
\hline
\end{tabular}

Note. $\mathrm{AQ}=$ Autism Quotient; REMT = Reading the Mind in the Eyes Test; ToM = Theory of Mind; ADOS= Autism Diagnostic Observation Scale ; SCQ = Social Communication Questionnaire; ADOS-2 = Autism Diagnostic Observation Scale, Second Edition; Vineland II = Vineland Adaptive Behaviour Scales, Second Edition; ADI-R = Autism Diagnostic Interview- Revised; SRS = Social Responsiveness Scale; SRS-2 = Social Responsiveness Scale 2; NEPSY-II = NEuroPSYschological Assessment Second Edition; SCDC = Social and Communication Disorders Checklist; IDT $=$ Interactive Drawing Test 
Table 4

Overview of Self-Report Measures

\begin{tabular}{|c|c|c|c|}
\hline Author (Year) & $\begin{array}{l}\text { Operationalisation of } \\
\text { camouflaging }\end{array}$ & Measure/s & Evidence of Validity and Reliability \\
\hline \multicolumn{4}{|l|}{ Adult Studies } \\
\hline $\begin{array}{l}\text { Hull et al. } \\
(2017)\end{array}$ & $\begin{array}{l}\text { Self-reported experience of } \\
\text { camouflaging }\end{array}$ & $\begin{array}{l}\text { Single item measuring } \\
\text { presence or absence of } \\
\text { camouflaging }\end{array}$ & $\begin{array}{l}\text { Questionnaire was developed in consultation with expert } \\
\text { clinicians, researchers, and autistic adults. }\end{array}$ \\
\hline $\begin{array}{l}\text { Cage et al. } \\
\text { (2018) }\end{array}$ & $\begin{array}{l}\text { Spontaneous reporting of } \\
\text { masking or camouflaging in text } \\
\text { response to questions }\end{array}$ & $\begin{array}{l}\text { Mixed methods } \\
\text { questionnaire examining } \\
\text { the relationship between } \\
\text { autism acceptance and } \\
\text { mental health. }\end{array}$ & n.r. \\
\hline $\begin{array}{l}\text { Cassidy et al. } \\
(2018)\end{array}$ & $\begin{array}{l}\text { Self-reported tendency to } \\
\text { camouflage }\end{array}$ & $\begin{array}{l}\text { Set of four items } \\
\text { measuring engagement in } \\
\text { camouflaging. }\end{array}$ & $\begin{array}{l}\text { Items were developed in consultation with autistic adults. } \\
\text { Internal consistency for the total score was } \alpha=.75 \text {. }\end{array}$ \\
\hline \multirow{2}{*}{$\begin{array}{l}\text { Cage and } \\
\text { Troxell- } \\
\text { Whitman } \\
\text { (2019) }\end{array}$} & $\begin{array}{l}1 \text { Self-reported use of } \\
\text { camouflaging strategies or } \\
\text { behaviours }\end{array}$ & 1. CAT-Q & $\begin{array}{l}\text { 1. In this sample, internal consistency for the total CAT-Q } \\
\text { score was } \alpha=0.89 \text {. }\end{array}$ \\
\hline & $\begin{array}{l}\text { 2. Self-reported camouflaging } \\
\text { contexts }\end{array}$ & $\begin{array}{l}\text { 2. Set of } 22 \text { items } \\
\text { measuring camouflaging } \\
\text { contexts }\end{array}$ & $\begin{array}{l}\text { 2. Camouflaging context items were developed in } \\
\text { consultation with autistic adults. Internal consistency for } \\
\text { the total score was } \alpha=0.95 \text {. Switchers and high } \\
\text { camouflagers demonstrated equivalent CAT-Q scores. }\end{array}$ \\
\hline $\begin{array}{l}\text { Hull et al. } \\
\text { (2019) }\end{array}$ & $\begin{array}{l}\text { Self-reported use of } \\
\text { camouflaging strategies or } \\
\text { behaviours }\end{array}$ & CAT-Q & $\begin{array}{l}\text { Items on questionnaire developed based on qualitative } \\
\text { study of autistic adults' experiences of camouflaging. } \\
\text { Questionnaire validated in a sample of } 832 \text { autistic and } \\
\text { non-autistic adults. Internal consistency for the total CAT-Q } \\
\text { score (with combined autistic and non-autistic samples) } \\
\text { was } \alpha=0.94 \text {. Internal consistencies for subscales were: } \\
\text { Compensation ( } \alpha=0.92 \text { ), Masking ( } \alpha=0.86 \text { ), and }\end{array}$ \\
\hline
\end{tabular}




\begin{tabular}{|c|c|c|c|}
\hline & & & $\begin{array}{l}\text { Assimilation ( } \alpha=0.93 \text { ). Test-rest reliability ( } r=0.77 \text { ) was } \\
\text { good in a subsample of autistic participants. }\end{array}$ \\
\hline $\begin{array}{l}\text { Livingston, } \\
\text { Shah, \& Happé } \\
\text { (2019) }\end{array}$ & $\begin{array}{l}\text { References to social } \\
\text { compensatory strategies in text } \\
\text { responses to questions }\end{array}$ & $\begin{array}{l}\text { Qualitative questionnaire } \\
\text { exploring social } \\
\text { compensatory strategies }\end{array}$ & n.r. \\
\hline $\begin{array}{l}\text { Beck et al. } \\
\text { (2020) }\end{array}$ & $\begin{array}{l}\text { Self-reported use of } \\
\text { camouflaging strategies or } \\
\text { behaviours }\end{array}$ & CAT-Q & n.r. using study sample \\
\hline $\begin{array}{l}\text { Brown et al. } \\
(2020)\end{array}$ & $\begin{array}{l}\text { Self-reported engagement in the } \\
\text { active process of developing and } \\
\text { displaying strategies that } \\
\text { minimize the impact of social } \\
\text { challenges }\end{array}$ & $\begin{array}{l}\text { Camouflaging subscale on } \\
\text { a modified version of GQ- } \\
\text { ASC }\end{array}$ & $\begin{array}{l}\text { Internal consistency for Camouflaging subscale was } \omega= \\
0.67 \text {. }\end{array}$ \\
\hline $\begin{array}{l}\text { Cage and } \\
\text { Troxell- } \\
\text { Whitman } \\
\text { (2020) }\end{array}$ & $\begin{array}{l}\text { Self-reported use of } \\
\text { camouflaging strategies or } \\
\text { behaviours }\end{array}$ & CAT-Q & $\begin{array}{l}\text { In this sample, internal consistency for the total CAT-Q } \\
\text { score was } \alpha=0.89 \text {. }\end{array}$ \\
\hline $\begin{array}{l}\text { Hull, Lai, et al. } \\
(2020)\end{array}$ & $\begin{array}{l}\text { Self-reported use of } \\
\text { camouflaging strategies or } \\
\text { behaviours }\end{array}$ & CAT-Q & $\begin{array}{l}\text { In this sample internal consistency for the total CAT-Q } \\
\text { score was } \alpha=0.94 \text {. }\end{array}$ \\
\hline $\begin{array}{l}\text { Livingston et al. } \\
\text { (2020) }\end{array}$ & $\begin{array}{l}\text { References to social } \\
\text { compensatory strategies in text } \\
\text { responses to questions }\end{array}$ & Compensation Checklist & $\begin{array}{l}\text { Items on the checklist were developed based on } \\
\text { qualitative study of autistic and non-autistic adults' } \\
\text { experiences of compensation. Greatest lower bound } \\
\text { reliability was glb=0.82. }\end{array}$ \\
\hline $\begin{array}{l}\text { Robsinson et al. } \\
(2020)\end{array}$ & $\begin{array}{l}\text { Self-reported use of } \\
\text { camouflaging strategies or } \\
\text { behaviours }\end{array}$ & CAT-Q & $\begin{array}{l}\text { In this sample, internal consistency for the total CAT-Q } \\
\text { score was } \alpha=0.94 \text {. Internal consistencies for the subscales } \\
\text { were: Compensation ( } \alpha=0.94) \text {, Masking ( } \alpha=0.80) \text {, and } \\
\text { Assimilation }(\alpha=0.90) \text {. }\end{array}$ \\
\hline $\begin{array}{l}\text { Cook, Crane, } \\
\text { Bourne et al. } \\
(2021)\end{array}$ & $\begin{array}{l}\text { Self-reported use of } \\
\text { camouflaging strategies or } \\
\text { behaviours }\end{array}$ & CAT-Q & $\begin{array}{l}\text { In this sample, internal consistency for the Total CAT-Q } \\
\text { score was } \alpha=0.84 \text {. }\end{array}$ \\
\hline $\begin{array}{l}\text { Hull, Levey, et } \\
\text { al. (2021) }\end{array}$ & $\begin{array}{l}\text { Self-reported use of } \\
\text { camouflaging strategies or } \\
\text { behaviours }\end{array}$ & CAT-Q & $\begin{array}{l}\text { In this sample, internal consistency for the Total CAT-Q } \\
\text { was } \alpha=0.79 \text {. }\end{array}$ \\
\hline
\end{tabular}




\begin{tabular}{|c|c|c|c|}
\hline $\begin{array}{l}\text { Perry et al. } \\
(2021)\end{array}$ & $\begin{array}{l}\text { Self-reported use of } \\
\text { camouflaging strategies or } \\
\text { behaviours }\end{array}$ & CAT-Q & $\begin{array}{l}\text { In this sample, internal consistency for the Total CAT-Q } \\
\text { was } \alpha=0.90 \text {. }\end{array}$ \\
\hline \multicolumn{4}{|c|}{ Child/Adolescent Studies } \\
\hline $\begin{array}{l}\text { Ormond et al. } \\
\text { (2018) }\end{array}$ & $\begin{array}{l}\text { Parent-reported level of masking } \\
\text { emotional responses and } \\
\text { expressions during social } \\
\text { interactions }\end{array}$ & $\begin{array}{l}\text { Social Masking subscale } \\
\text { on the Q-ASC. }\end{array}$ & $\begin{array}{l}\text { Internal consistency for the Social Masking subscale was } 0 \\
=.61 \text {. }\end{array}$ \\
\hline $\begin{array}{l}\text { Hull, Petrides, } \\
\text { \& Mandy } \\
(2021)\end{array}$ & $\begin{array}{l}\text { Self-reported use of } \\
\text { camouflaging strategies or } \\
\text { behaviours }\end{array}$ & CAT-Q & $\begin{array}{l}\text { In this sample, internal consistency for the total CAT-Q } \\
\text { score was } \alpha=0.91 \text {. Internal consistencies for subscales } \\
\text { were: Compensation ( } \alpha=0.89 \text { ), Masking ( } \alpha=0.81 \text { ), and } \\
\text { Assimilation }(\alpha=0.87) \text {. }\end{array}$ \\
\hline $\begin{array}{l}\text { Jorgenson et al. } \\
(2020)\end{array}$ & $\begin{array}{l}\text { Self-reported use of } \\
\text { camouflaging strategies or } \\
\text { behaviours }\end{array}$ & CAT-Q & $\begin{array}{l}\text { In this sample, internal consistency for the total CAT-Q } \\
\text { score was } \alpha=0.86 \text {. }\end{array}$ \\
\hline $\begin{array}{l}\text { Bernardin et al. } \\
\text { (2021) }\end{array}$ & $\begin{array}{l}\text { Self-reported use of } \\
\text { camouflaging strategies or } \\
\text { behaviours }\end{array}$ & CAT-Q & $\begin{array}{l}\text { In this sample, internal consistency for the Total CAT-Q } \\
\text { score was } \alpha=0.86 \text {. }\end{array}$ \\
\hline $\begin{array}{l}\text { Jedrzejewska \& } \\
\text { Dewey (2021) }\end{array}$ & $\begin{array}{l}\text { Self-reported use of } \\
\text { camouflaging strategies or } \\
\text { behaviours }\end{array}$ & $\begin{array}{l}\text { 1. CAT-Q } \\
\text { 2. CATO-Q }\end{array}$ & $\begin{array}{l}\text { 1. n.r. in study sample } \\
\text { 2. n.r. }\end{array}$ \\
\hline
\end{tabular}


Table 5

Summary of Evidence Presented in Included Studies Grouped by Research Question.

\begin{tabular}{|c|c|c|c|c|c|}
\hline Author (year) & $\begin{array}{l}\text { Q1: Is } \\
\text { Camouflaging } \\
\text { associated } \\
\text { with having } \\
\text { high autistic } \\
\text { traits or an } \\
\text { autism } \\
\text { diagnosis? }\end{array}$ & $\begin{array}{l}\text { Q2: Are } \\
\text { there sex or } \\
\text { gender } \\
\text { differences } \\
\text { in } \\
\text { camouflaging } \\
\text { behaviours? }\end{array}$ & $\begin{array}{l}\text { Q3: Are } \\
\text { particular } \\
\text { cognitive } \\
\text { abilities or } \\
\text { processes } \\
\text { associated } \\
\text { with } \\
\text { camouflaging? }\end{array}$ & $\begin{array}{l}\text { Q4: Is } \\
\text { camouflaging } \\
\text { related to } \\
\text { current age or } \\
\text { age at } \\
\text { diagnosis? }\end{array}$ & $\begin{array}{l}\text { Q5: What is the } \\
\text { relationship } \\
\text { between } \\
\text { camouflaging } \\
\text { and mental } \\
\text { health and } \\
\text { wellbeing } \\
\text { outcomes? }\end{array}$ \\
\hline \multicolumn{6}{|c|}{ Internal-external discrepancy adult studies } \\
\hline Lai et al. (2017) & & $\checkmark$ & $\checkmark$ & $x$ & $\checkmark$ \\
\hline Schuck et al. (2019) & & $\checkmark$ & $x$ & & $x$ \\
\hline \multicolumn{6}{|l|}{ Self-report adult studies } \\
\hline Hull et al. (2017) & & $x$ & & & \\
\hline Cage et al. (2018) & $\sqrt{ }{ }^{a}$ & $x$ & & & $\checkmark$ \\
\hline Cassidy et al. (2018) & & $\checkmark$ & & $x$ & $\checkmark$ \\
\hline $\begin{array}{l}\text { Cage and Troxell- } \\
\text { Whitman (2019) }\end{array}$ & & $x$ & & $x$ & $\checkmark$ \\
\hline Hull et al. (2019) & $\checkmark$ & & & & $\checkmark$ \\
\hline $\begin{array}{l}\text { Livingston, Shah, \& } \\
\text { Happé (2019) }\end{array}$ & $x$ & & & & \\
\hline Beck et al. (2020) & & & & & $\checkmark$ \\
\hline Brown et al. (2020) & $\checkmark$ & & & & \\
\hline $\begin{array}{l}\text { Cage and Troxell- } \\
\text { Whitman (2020) }\end{array}$ & $\sqrt{ }^{\mathrm{b}}$ & & & & \\
\hline Hull, Lai, et al. (2020) & & $\checkmark$ & & & \\
\hline Livingston et al. (2020) & $\checkmark$ & $x$ & & $x$ & \\
\hline Robinson et al. (2020) & & & & & $\checkmark$ \\
\hline Hull, Levy, et al. (2021) & & & & & $\checkmark$ \\
\hline Perry et al. (2021) & $\sqrt{ } \mathrm{c}$ & $\checkmark$ & & $\checkmark$ & $x$ \\
\hline \multicolumn{6}{|c|}{ Internal-external discrepancy child/adolescent studies } \\
\hline Rynkiewcz et al. (2016) & & $\checkmark$ & & & \\
\hline $\begin{array}{l}\text { Parish-Morris et al. } \\
(2017)\end{array}$ & & $\checkmark$ & & & \\
\hline Ratto et al. (2018) & & $\checkmark$ & & & \\
\hline $\begin{array}{l}\text { Livingston, Colvert, et } \\
\text { al. (2019) }\end{array}$ & & $x$ & $\checkmark$ & $x$ & $\checkmark$ \\
\hline Corbett et al. (2021) & & $\checkmark$ & $x$ & & $\checkmark$ \\
\hline Wood-Downie (2020) & & $\checkmark$ & $\checkmark$ & & \\
\hline \multicolumn{6}{|c|}{ Self/parent report child/adolescent studies } \\
\hline Ormond et al (2018) & & $\checkmark$ & & $\checkmark$ & \\
\hline $\begin{array}{l}\text { Hull, Petrides, \& } \\
\text { Mandy (2021) }\end{array}$ & & & $\checkmark$ & $x$ & \\
\hline Jorgenson et al. (2020) & $x$ & $x$ & & $x$ & \\
\hline Bernardin et al. (2021) & & & & & $\checkmark$ \\
\hline $\begin{array}{l}\text { Jedrzejewska \& Dewey } \\
\text { (2021) }\end{array}$ & $\checkmark$ & $\checkmark$ & & & \\
\hline
\end{tabular}

Note: $\checkmark=$ indicated significant findings with respect to at least one variable; $x=$ indicates the research question was investigated but no significant finding was identified

a experiences of autism acceptance 
b autistic identity

${ }^{\mathrm{c}}$ stigma 


\section{Appendix A}

\section{Database Search Strategy}

Database: Ovid MEDLINE(R) and Epub Ahead of Print, In-Process \& Other Non-Indexed Citations and Daily from 1946

\section{Search Strategy:}

1 exp child development disorders, pervasive/ or autism spectrum disorder/ or asperger syndrome/ or autistic disorder/

2 autis*.mp.

3 asperger*.mp.

4 (pervasiv* adj2 development* adj2 disorder*).mp. [mp=title, abstract, original title, name of substance word, subject heading word, floating sub-heading word, keyword heading word, organism supplementary concept word, protocol supplementary concept word, rare disease supplementary concept word, unique identifier, synonyms]

5 ASD.mp.

61 or 2 or 3 or 4 or 5

7 Social Conformity/

8 (peer imitation or social imitation).mp. [mp=title, abstract, original title, name of substance word, subject heading word, floating sub-heading word, keyword heading word, organism supplementary concept word, protocol supplementary concept word, rare disease supplementary concept word, unique identifier, synonyms]

9 camouflag*.mp. [mp=title, abstract, original title, name of substance word, subject heading word, floating sub-heading word, keyword heading word, organism supplementary concept word, protocol supplementary concept word, rare disease supplementary concept word, unique identifier, synonyms] 
10 (compensat* adj20 (autis* or asperger* or ASD or social or behav* or mask* or camouflag* or strategies)).mp. [mp=title, abstract, original title, name of substance word, subject heading word, floating sub-heading word, keyword heading word, organism supplementary concept word, protocol supplementary concept word, rare disease supplementary concept word, unique identifier, synonyms]

11 (pass adj20 (autis* or asperger* or ASD or social or behav* or mask* or camouflag* or strategies)).mp. [mp=title, abstract, original title, name of substance word, subject heading word, floating sub-heading word, keyword heading word, organism supplementary concept word, protocol supplementary concept word, rare disease supplementary concept word, unique identifier, synonyms]

12 (passing adj20 (autis* or asperger* or ASD or social or behav* or mask* or camouflag* or strategies)).mp. [mp=title, abstract, original title, name of substance word, subject heading word, floating sub-heading word, keyword heading word, organism supplementary concept word, protocol supplementary concept word, rare disease supplementary concept word, unique identifier, synonyms]

13 (mask* adj20 (autis* or asperger* or ASD or social or behav* or pass or passing or camouflag* or strategies)).mp. [mp=title, abstract, original title, name of substance word, subject heading word, floating sub-heading word, keyword heading word, organism supplementary concept word, protocol supplementary concept word, rare disease supplementary concept word, unique identifier, synonyms]

147 or 8 or 9 or 10 or 11 or 12 or 13

156 and 14

Database: Embase from 1980

\section{Search Strategy:}


1 autism/ or asperger syndrome/ or "pervasive developmental disorder not otherwise specified"/

2 autis*.mp.

3 asperger*.mp.

4 (pervasiv* adj2 development* adj2 disorder*).mp. [mp=title, abstract, heading word, drug trade name, original title, device manufacturer, drug manufacturer, device trade name, keyword, floating subheading word, candidate term word]

5 ASD.mp.

61 or 2 or 3 or 4 or 5

7 compensation/

8 masking/

9 (peer imitation or social imitation).mp. [mp=title, abstract, heading word, drug trade name, original title, device manufacturer, drug manufacturer, device trade name, keyword, floating subheading word, candidate term word]

10 camouflag*.mp. [mp=title, abstract, heading word, drug trade name, original title, device manufacturer, drug manufacturer, device trade name, keyword, floating subheading word, candidate term word]

11 (compensat* adj20 (autis* or asperger* or ASD or social or behav* or mask* or camouflag* or strategies)).mp. [mp=title, abstract, heading word, drug trade name, original title, device manufacturer, drug manufacturer, device trade name, keyword, floating subheading word, candidate term word]

12 (pass adj20 (autis* or asperger* or ASD or social or behav* or mask* or camouflag* or strategies)).mp. [mp=title, abstract, heading word, drug trade name, original title, device manufacturer, drug manufacturer, device trade name, keyword, floating subheading word, candidate term word] 
13 (passing adj20 (autis* or asperger* or ASD or social or behav* or mask* or camouflag* or strategies)).mp. [mp=title, abstract, heading word, drug trade name, original title, device manufacturer, drug manufacturer, device trade name, keyword, floating subheading word, candidate term word]

14 (mask* adj20 (autis* or asperger* or ASD or social or behav* or pass or passing or camouflag* or strategies)).mp. [mp=title, abstract, heading word, drug trade name, original title, device manufacturer, drug manufacturer, device trade name, keyword, floating subheading word, candidate term word]

157 or 8 or 9 or 10 or 11 or 12 or 13 or 14

$16 \quad 6$ and 15

Database: APA Psych Info (Ovid) from 1806

\section{Search Strategy:}

1 autism spectrum disorders/ or neurodevelopmental disorders/ or autistic traits/

2 autis*.mp.

3 asperger*.mp.

4 (pervasiv* adj2 development* adj2 disorder*).mp. [mp=title, abstract, heading word, table of contents, key concepts, original title, tests \& measures, mesh]

5 ASD.mp.

61 or 2 or 3 or 4 or 5

7 "compensation (defense mechanism)"/

8 (peer imitation or social imitation).mp. [mp=title, abstract, heading word, table of contents, key concepts, original title, tests \& measures, mesh]

9 camouflag*.mp. [mp=title, abstract, heading word, table of contents, key concepts, original title, tests \& measures, mesh] 
10 (compensat* adj20 (autis* or asperger* or ASD or social or behav* or mask* or camouflag* or strategies)).mp. [mp=title, abstract, heading word, table of contents, key concepts, original title, tests \& measures, mesh]

11 (pass adj20 (autis* or asperger* or ASD or social or behav* or mask* or camouflag* or strategies)).mp. [mp=title, abstract, heading word, table of contents, key concepts, original title, tests \& measures, mesh]

12 (passing adj20 (autis* or asperger* or ASD or social or behav* or mask* or camouflag* or strategies)).mp. [mp=title, abstract, heading word, table of contents, key concepts, original title, tests \& measures, mesh]

13 (mask* adj20 (autis* or asperger* or ASD or social or behav* or pass or passing or camouflag* or strategies)).mp. [mp=title, abstract, heading word, table of contents, key concepts, original title, tests \& measures, mesh]

147 or 8 or 9 or 10 or 11 or 12 or 13

156 and 14

Database: Scopus

Search Strategy:

( TITLE-ABS-KEY ( autis* OR asperger* OR asd OR ( pervasive AND development* AND disorder*)) ) AND ( ( TITLE-ABS-KEY ( camouflag*)) OR ( TITLE-ABS-KEY ( ( peer AND imitation) OR ( social AND imitation )) ) OR ( TITLE-ABS-KEY ( compensat* W/20 (autis* OR asperger* OR asd OR social OR behav* OR mask* OR camouflag* OR strategies)) ) OR (TITLE-ABS-KEY (pass W/20 ( autis* OR asperger* OR asd OR social OR behav* OR mask* OR camouflag* OR strategies ))) OR (TITLEABS-KEY (passing W/20 (autis* OR asperger* OR asd OR social OR behav* OR mask* OR camouflag* OR strategies )) ) OR (TITLE-ABS-KEY (mask W/20 (autis* OR asperger* OR asd OR 
social OR behav* OR mask* OR camouflag* OR strategies))) OR (TITLE-ABS-KEY ( masking W/20 (autis* OR asperger* OR asd OR social OR behav* OR mask* OR camouflag* OR strategies )))) Database: Web of Science Core Collection from 1900

Search Strategy:

31 and 2

2 TS=(camouflag*) OR TS=("peer imitation" or "social imitation") OR TS=((compensat* near/20 (auti $\mathrm{s}^{*}$ or asperger* or ASD or social or behav* or mask* or camouflag* or strategies) )) OR TS=((pass near/20 (autis* or asperger* or ASD or social or behav* or mask* or camouflag* or strategies) )) OR TS=((passing near/20 (autis* or asperger* or ASD or social or behav* or mask* or camouflag* or strategies) $))$ OR TS=((mask* near/20 (autis* or asperger* or ASD or social or behav* or pass or passing or camouflag* or strategies) ))

1 TOPIC: (autis*) OR TOPIC: (asperger*) OR TOPIC: (((pervasiv* near/1 development*) AND disorder*)) OR TOPIC: (ASD)

Database: ProQuest Dissertations and Theses

Search Strategy:

(ti(autis* OR asperger* OR ASD) AND ti(camouflag* OR "compensatory strategies")) OR (ab(autis* OR asperger* OR ASD) AND ab(camouflag* OR "compensatory strategies"))

Database: Google Scholar

Search Strategy:

1 allintitle: Autism camouflaging OR camouflage OR "peer imitation" OR "social imitation" OR passing OR masking OR "compensatory strategies"

2 allintitle: Autistic camouflaging OR camouflage OR "peer imitation" OR "social imitation" OR passing OR masking OR "compensatory strategies"

Database: PsyARXIV 
Search Strategy:

autis* AND ( camouflag* OR compensat* OR passing OR masking OR "peer imitation" OR "social imitation") 


\section{Appendix B}

\section{Table 6}

Overview of Exclusion Reasons for Articles Previously Included in Allely (2019) and Tubio-Fungueiriño et al. (2020).

\begin{tabular}{ll}
\hline Author and Year & Reason for Exclusion \\
\hline Bargiela et al. (2016) & $\begin{array}{l}\text { Presented only qualitative data regarding camouflaging in late diagnosed } \\
\text { Cooken. }\end{array}$ \\
Dean et al. (2017) & $\begin{array}{l}\text { Presented only qualitative data regarding masking in autistic girls and } \\
\text { their mothers. }\end{array}$ \\
& $\begin{array}{l}\text { This study quantitatively compared playground activities (type of activity } \\
\text { and time spent in activity) between autistic and non-autistic boys and } \\
\text { girls. Qualitive data was provided describing camouflaging behaviours. }\end{array}$ \\
& $\begin{array}{l}\text { Thus, this study did not present quantitative data measuring } \\
\text { camouflaging. } \\
\text { Head et al. (2014) }\end{array}$ \\
& $\begin{array}{l}\text { The authors compared autistic and non-autistic children's scores on a } \\
\text { self-report measure of friendship quality, understanding, and empathy. } \\
\text { Thus, this study did not report quantitative data measuring } \\
\text { camouflaging. }\end{array}$ \\
Lehnhardt et al. (2016) & $\begin{array}{l}\text { The authors compared differences in cognitive, executive functioning, } \\
\text { and mentalising abilities between late diagnosed autistic men and } \\
\text { women. The authors discussed these abilities as potentially enabling } \\
\text { camouflaging. Thus, this study presented data on abilities that may be } \\
\text { associated with camouflaging rather than camouflaging per se. } \\
\text { Presented only qualitative data regarding camouflaging in autistic girls. }\end{array}$ \\
\hline
\end{tabular}




\section{Appendix C}

Table 7

Results of Quality Assessment using MMAT.

Quality Criteria

$\mathrm{N}$ studies

Reasons studies did not meet criteria (i.e. received a "no" or "can't tell" meeting Criteria rating)

Quantitative/mixed methods studies ( $\mathrm{n}$

= 26)

\author{
Are participants \\ representative of the \\ target population?
}

Are measurements appropriate (e.g., justified, appropriate, validated, and reliability tested)?
- Target population was autistic people, however those with ID were excluded/not invited to participate $(n=10)$

- Target population was autistic adults, however, online format is a barrier to participation for those with certain intellectual or language difficulties ( $\mathrm{n}=11$ )

- Sample was predominately female (not including studies with gender related hypothesis; $n=5$ )

- Sample was predominately diagnosed in adulthood $(n=4)$

- Data come from larger data set and no information provided regarding differences between participants included and large number of participants excluded $(n=1)$

- Target population was autistic people, however reported IQ range does not include $\mathrm{IQ}<70(\mathrm{n}=1)$

- Measure/s not designed for use with autistic people and no information provided regarding the suitability of these measures for use with autistic population/no reliability data provided for current sample $(n=3$ )

- Measure/s not designed for specific age group of autistic people and no information provided regarding the suitability of measure/s for use with this age group/no reliability data provided for current sample $(n=1)$

- Ad hoc method of quantifying camouflaging or compensation scores based on text responses to open ended question $(n=2)$ 
Is outcome data

complete?

Are confounders

considered and

accounted for in the

design and analysis?

Qualitative studies
$(n=3)$

Qualitative approach is

appropriate for the

research question

Adequate data

collection methods

Findings derived from

the data

Interpretation of

results sufficiently

substantiated by data

Coherence between

qualitative data

sources, collection,

analysis and

interpretation
- Measured main variable of gender using single question where the only response options were male and female $(n=1)$

- Measured main variable of interest using single item, thereby limiting individual variation that could be captured $(n=1)$

- $>20 \%$ of data missing on a main variable $(n=2)$

- Flow of participants not provided $(n=17)$

- Amount of missing data unclear $(n=1)$

- Main analysis involved between group comparison, however, no statistics were provided regarding potential between group differences on demographic variables $(n=10)$

- Autistic and non-autistic group compared, however, autistic traits were not controlled for $(n=2)$ 


\section{Appendix D}

\section{Table 8}

Overview of Participant Characteristics for Included Studies

\begin{tabular}{|c|c|c|c|c|c|c|c|c|c|}
\hline $\begin{array}{l}\text { Author } \\
\text { (year) }\end{array}$ & $\begin{array}{l}\mathrm{N}(\mathrm{n}= \\
\text { sex/gender); } \\
\text { measurement }\end{array}$ & $\begin{array}{l}\text { Mean age, } \\
(S D) \text {, range }\end{array}$ & $\begin{array}{l}\% \text { Clinical } \\
\text { diagnosis } \\
\text { of autism }\end{array}$ & $\begin{array}{l}\text { Mean age at } \\
\text { diagnosis } \\
\text { (SD) }\end{array}$ & $\begin{array}{l}\text { Mean FSIQ } \\
\text { (SD); } \\
\text { measure }\end{array}$ & $\begin{array}{l}\% \text { Ethnic group } \\
\text { or race }\end{array}$ & $\begin{array}{l}\text { \% Educational } \\
\text { attainment }\end{array}$ & \% Comorbidities & $\begin{array}{l}\text { Location; } \\
\text { Recruitment } \\
\text { methods }\end{array}$ \\
\hline $\begin{array}{l}\text { Hull et al. } \\
\text { (2017) }\end{array}$ & $\begin{array}{l}92 \mathrm{ASD}(\mathrm{n}= \\
55 \mathrm{~F}, 30 \mathrm{M}, 7 \\
\text { O); gender } \\
(n=65 \mathrm{~F}, 27 \\
\text { M); sex }\end{array}$ & $\begin{array}{l}\text { F: 40.71 } \\
(14.14), 18- \\
68 ; \\
M: 48.03 \\
(16.62), 22- \\
79 ; \\
O: 40.71 \\
(14.29), 27- \\
69\end{array}$ & 100 & $\begin{array}{l}\text { F: } 36.98 \\
(14.21) ; \\
M: 41.03 \\
(18.08) ; \\
O: 32.67 \\
(9.25)\end{array}$ & n.r. & n.r. & n.r. & n.r. & $\begin{array}{l}\text { Worldwide; } \\
\text { Recruitment via } \\
\text { CARD and adverts } \\
\text { placed on social } \\
\text { media. }\end{array}$ \\
\hline $\begin{array}{l}\text { Lai et al. } \\
\text { (2017) }\end{array}$ & $\begin{array}{l}60 \text { ASD }(n= \\
30 \mathrm{~F}, 30 \mathrm{M}) \\
\text { sex/gender }\end{array}$ & $\begin{array}{l}\text { F: } 27.8(7.6) \\
18-49^{\mathrm{a}} ; \\
\mathrm{M}: 27.2(7.3)\end{array}$ & 100 & n.r. & $\begin{array}{l}\text { F: } 114.9 \\
(13.8) ; \\
\text { M: } 115.4 \\
(14.1) ; \\
\text { WASI }\end{array}$ & n.r. & n.r. & n.r. & $\begin{array}{l}\text { UK; Recruitment via } \\
\text { CARD, referral from } \\
\text { diagnostic clinics for } \\
\text { adults with autism } \\
\text { or Asperger's } \\
\text { Syndrome and } \\
\text { advertisements } \\
\text { placed with } \\
\text { national and local } \\
\text { autism support } \\
\text { organisations and } \\
\text { support groups. }\end{array}$ \\
\hline
\end{tabular}




\begin{tabular}{|c|c|c|c|c|c|c|c|c|c|}
\hline $\begin{array}{l}\text { Cage et al. } \\
(2018)\end{array}$ & $\begin{array}{l}111 \text { ASD ( } n= \\
62 \mathrm{~F}, 28 \mathrm{M}, 12 \\
\text { O, } 1 \text { TG, } 1 \\
\text { N.R.); gender }\end{array}$ & $\begin{array}{l}36.4(12.0), \\
18-72\end{array}$ & 90 & $31.4(14.0)$ & n.r. & $\begin{array}{l}70 \text { White } \\
\text { British; } 18 \\
\text { Other white } \\
\text { background; } 4 \\
\text { Mixed } \\
\text { ethnicity; } 1 \\
\text { Asian; } 4 \text { Other; } \\
3 \text { Prefer not to } \\
\text { say }\end{array}$ & $\begin{array}{l}4 \text { No } \\
\text { qualifications; } 9 \\
\text { 1-4 GCSEs or } \\
\text { equivalent 9; } 7 \\
\text { 5+ GCSEs or } \\
\text { equivalent; } 1 \\
\text { Apprenticeship; } \\
11 \text { 2+ A-levels or } \\
\text { equivalent; } 31 \\
\text { Undergraduate } \\
\text { degree; } 24 \\
\text { Masters degree; } \\
3 \text { Doctoral } \\
\text { degree; } 8 \text { Other } \\
\text { qualifications; } 4 \\
\text { Prefer not to } \\
\text { say }\end{array}$ & $\begin{array}{l}\text { 51.4 Depression; } \\
\text { 55.9 Anxiety; } 31.5 \\
\text { Social anxiety; } \\
\text { 16.2 Attention } \\
\text { deficit } \\
\text { hyperactivity } \\
\text { disorder; } 16.2 \\
\text { Obsessive } \\
\text { compulsive } \\
\text { disorder; } 8.1 \\
\text { Post-traumatic } \\
\text { stress disorder; } \\
6.3 \text { Bi-polar; } 3.6 \\
\text { Tourette's } \\
\text { syndrome }\end{array}$ & $\begin{array}{l}\text { UK; Advertisements } \\
\text { distributed via } \\
\text { social media and } \\
\text { autism } \\
\text { organisations and } \\
\text { groups. }\end{array}$ \\
\hline $\begin{array}{l}\text { Cassidy et } \\
\text { al. (2018) }\end{array}$ & $\begin{array}{l}164 \text { ASD }(n= \\
99 \text { F, } 65 \text { M); } \\
\text { sex }\end{array}$ & $\begin{array}{l}\text { F: } 38.89, \\
(10.47), 20- \\
60^{\text {b }} \\
M: 41.52 \\
(11.73)\end{array}$ & 100 & $\begin{array}{l}\text { F: } 35.06 \\
(11.83) ; \\
\text { M: } 34.55 \\
(14.75)\end{array}$ & n.r. & n.r. & n.r. & $\begin{array}{l}\text { 79.9 Depression; } \\
\text { 71.3 Anxiety; } \\
\text { 14.6 Obsessive } \\
\text { compulsive } \\
\text { disorder; } 7.3 \\
\text { Bipolar disorder; } \\
14 \text { Personality } \\
\text { disorder; } 3.7 \\
\text { Schizophrenia; } \\
\text { 5.5 Anorexia; } 1.2 \\
\text { Bulimia; } 7.9 \\
\text { Myalgic } \\
\text { encephalopathy; } \\
\text { 2.4 Tourettes; } 3 \\
\text { Epilepsy; } 18.9 \\
\text { Other }\end{array}$ & $\begin{array}{l}\text { Worldwide; } \\
\text { Recruitment via } \\
\text { CARD and adverts } \\
\text { placed online. }\end{array}$ \\
\hline
\end{tabular}




\begin{tabular}{|c|c|c|c|c|c|c|c|c|c|}
\hline & $\begin{array}{l}169 \text { TD }(n= \\
115 \mathrm{~F}, 54 \mathrm{M}) \\
\text { sex }\end{array}$ & $\begin{array}{l}\text { F:41.48, } \\
\text { (11.18), n.r.; } \\
\text { M: 39.11, } \\
\text { (10.09), n.r. }\end{array}$ & & & & & & & \\
\hline $\begin{array}{l}\text { Cage and } \\
\text { Troxell- } \\
\text { Whitman } \\
\text { (2019) }\end{array}$ & $\begin{array}{l}262 \text { ASD } \\
\text { ( } n=135 \text { F, } \\
111 \text { M, O 12, } \\
4 \text { n.r.); gender }\end{array}$ & $\begin{array}{l}33.62 \\
(11.52) \text {, n.r. }\end{array}$ & 100 & $\begin{array}{l}21.2 \% \text { Under } \\
18 ; 42.8 \% \\
18-34 ; 36 \% \\
35-64\end{array}$ & n.r. & $\begin{array}{l}85.5 \text { White; } 8.4 \\
\text { Mixed/multi- } \\
\text { ethnic; } 2.7 \\
\text { Asian; } 1.9 \\
\text { Other; } 1.1 \\
\text { Prefer not to } \\
\text { say }\end{array}$ & n.r. & $\begin{array}{l}\text { 51.9 Anxiety; } 14.5 \\
\text { ADHD; } 3.1 \\
\text { Bipolar; } 50.8 \\
\text { Depression; } 7.6 \\
\text { Obsessive } \\
\text { compulsive } \\
\text { disorder; } 9.5 \\
\text { Post-traumatic } \\
\text { stress disorder; } \\
\text { 23.7 Social } \\
\text { anxiety disorder; } \\
\text { 1.9 Tourette's } \\
\text { syndrome; } 18.7 \\
\text { Other diagnosis }\end{array}$ & $\begin{array}{l}\text { UK'; Direct contact } \\
\text { via autism charities } \\
\text { and organisations } \\
\text { and advertisements } \\
\text { placed on social } \\
\text { media. }\end{array}$ \\
\hline \multirow[t]{2}{*}{$\begin{array}{l}\text { Hull et al. } \\
\text { (2019) }\end{array}$} & $\begin{array}{l}354 \text { ASD ( } n= \\
179 \mathrm{~F}, 108 \mathrm{M}, \\
17 \mathrm{O}, 50 \text { n.r.); } \\
\text { gender }\end{array}$ & $\begin{array}{l}41.93, \\
(13.55), 16- \\
82^{b}\end{array}$ & 100 & 34.2 (n.r.) & n.r. & n.r. & n.r. & n.r. & $\begin{array}{l}\text { UK'; Recruitment } \\
\text { via CARD and word } \\
\text { of mouth. }\end{array}$ \\
\hline & $\begin{array}{l}478 \text { TD }(n= \\
255 \mathrm{~F}, 192 \mathrm{M} \text {, } \\
29 \text { O); gender }\end{array}$ & $30.24(13.72)$ & & & & & & & \\
\hline $\begin{array}{l}\text { Lai et al. } \\
\text { (2019) }\end{array}$ & $\begin{array}{l}57 \text { ASD }(n= \\
28 F, 29 M) ; \\
\text { sex } \\
(n=28 F, 29 \\
M) ; \text { gender }\end{array}$ & $\begin{array}{l}F: 28.19 \\
(7.23), 18-45 ; \\
M: 26.59 \\
(7.04), 18-41\end{array}$ & 100 & n.r. & $\begin{array}{l}\text { F: } 114.46 \\
(13.56) ; \\
\text { M: } 114.14 \\
(16.42) ; \\
\text { WASI }\end{array}$ & $\begin{array}{l}98 \text { Caucasian; } 2 \\
\text { Mixed } \\
\text { Caucasian and } \\
\text { other ethnic } \\
\text { background }\end{array}$ & n.r. & $\begin{array}{l}\text { n.r.; Adults with } \\
\text { history or current } \\
\text { psychotic } \\
\text { disorders and } \\
\text { substance use } \\
\text { disorder } \\
\text { excluded. }\end{array}$ & $\begin{array}{l}\text { UK; Recruited via } \\
\text { CARD, referrals } \\
\text { from diagnostic } \\
\text { clinics for adults } \\
\text { with autism or } \\
\text { Asperger's } \\
\text { Syndrome, and } \\
\text { advertisements } \\
\text { placed with }\end{array}$ \\
\hline
\end{tabular}


national and local autism support

organisations and

support groups.

\begin{tabular}{|c|c|c|c|c|}
\hline $\begin{array}{l}62 \mathrm{TD}(\mathrm{n}=29 \\
\mathrm{F}, 33 \mathrm{M})\end{array}$ & $\begin{array}{l}F: 27.63, \\
(6.40), 18-45 ; \\
M: 27.94 \\
(6.08), 18-42\end{array}$ & n.r. & $\begin{array}{l}98 \text { Caucasian; } 2 \\
\text { Mixed } \\
\text { Caucasian and } \\
\text { other ethnic } \\
\text { background }\end{array}$ & \\
\hline
\end{tabular}

\begin{tabular}{|c|c|c|c|c|c|c|c|c|c|}
\hline $\begin{array}{l}\text { Livingston, } \\
\text { Shah \& } \\
\text { Happé } \\
\text { (2019) }\end{array}$ & $\begin{array}{l}77 \text { ASD }(n= \\
46 \mathrm{~F}, 21 \mathrm{M}, 10 \\
\text { O); gender }\end{array}$ & $\begin{array}{l}\text { D: } 35.8, \\
\text { (11.5), 18-70; } \\
\text { S.I.: 40.2, } \\
\text { (11.1), 25-64 }\end{array}$ & 75.3 & $30.1(13.8)$ & n.r. & n.r. & $\begin{array}{l}\text { D: } 4.7(2.1) \text {; S.I.: } \\
4.8(1.9)^{d}\end{array}$ & $\begin{array}{l}13 \\
\text { Developmental } \\
\text { disorders; } 39 \\
\text { Anxiety disorders; } \\
6.5 \text { Obsessive- } \\
\text { compulsive; } 23.4 \\
\text { Depressive } \\
\text { disorders; } 1.3 \\
\text { Bipolar disorder; } \\
1.3 \text { Eating } \\
\text { disorder; } 3.9 \\
\text { Trauma/stress } \\
\text { disorder; } 5.2 \\
\text { Other }\end{array}$ & $\begin{array}{l}\text { Worldwide; } \\
\text { Advertisements } \\
\text { distributed via } \\
\text { social media and } \\
\text { the UK National } \\
\text { Autistic Society. }\end{array}$ \\
\hline
\end{tabular}




\begin{tabular}{|c|c|c|c|c|c|c|c|c|}
\hline & $\begin{array}{l}59 \text { TD }(n=51 \\
F, 8 M) ; \\
\text { gender }\end{array}$ & $\begin{array}{l}33.9,(14.8) \\
18-77\end{array}$ & & & & $4.7(1.8)^{d}$ & $\begin{array}{l}\text { 3.4 } \\
\text { Developmental } \\
\text { Disorder; } 30.5 \\
\text { Anxiety disorder; } \\
3.4 \\
\text { Obsessive- } \\
\text { Compulsive; } 20.3 \\
\text { Depressive } \\
\text { disorder; } 1.7 \\
\text { Bipolar disorder; } \\
0 \text { Eating disorder; } \\
3.4 \\
\text { Personality } \\
\text { disorder; } 1.7 \\
\text { Trauma/stress } \\
\text { disorder; } 0 \\
\text { Schizophrenic } \\
\text { disorder; } 0 \text { Other }\end{array}$ & \\
\hline \multirow[t]{2}{*}{$\begin{array}{l}\text { Schuck et } \\
\text { al. (2019) } \\
\text { gender }\end{array}$} & $\begin{array}{l}28 \text { ASD }(n= \\
11 \mathrm{~F}, 17 \mathrm{M}) \\
\text { sex/gender }\end{array}$ & $\begin{array}{l}\text { F: } 33,(9.72), 100 \\
\text { n.r.; } \\
\text { M: } 23,(4.09), \\
\text { n.r. }\end{array}$ & n.r. & $\begin{array}{l}\text { F: 101 } \\
\text { (16.01); } \\
\text { M: 102 } \\
(16.77) ; \\
\text { Standford- } \\
\text { Binet } \\
\text { Intelligence } \\
\text { Scales, 5th } \\
\text { Ed. }\end{array}$ & $\begin{array}{l}75 \text { White; } 7 \\
\text { Asian; } 4 \\
\text { Hispanic; } 14 \\
\text { Unknown }\end{array}$ & n.r. & n.r. & $\begin{array}{l}\text { USA; Referral from } \\
\text { the Autism and } \\
\text { Developmental } \\
\text { Disabilities Clinic at } \\
\text { Stanford Children's } \\
\text { Health and flyers } \\
\text { placed at colleges. }\end{array}$ \\
\hline & $\begin{array}{l}34 \mathrm{TD}(\mathrm{n}=15 \\
\mathrm{F}, 19 \mathrm{M})\end{array}$ & $\begin{array}{l}\text { F: } 28,(8.03), \\
\text { n.r. } \\
\text { M: 26, (7.35), } \\
\text { n.r. }\end{array}$ & & & $\begin{array}{l}11.8 \text { White; } \\
\text { 41.2 Asian; } 5.9 \\
\text { Hispanic; } 11.8 \\
\text { Black; } 29.4 \\
\text { Unknown }\end{array}$ & & & \\
\hline
\end{tabular}




\begin{tabular}{|c|c|c|c|c|c|c|c|c|c|}
\hline $\begin{array}{l}\text { Beck et al. } \\
(2020)\end{array}$ & $\begin{array}{l}58 \text { ASD/ASD } \\
\text { traits ( } n=58 \\
\text { F); n.r. }\end{array}$ & $\begin{array}{l}\text { 25.2, (6.17), } \\
\text { n.r. }\end{array}$ & 31 & $\begin{array}{l}55.6 \% \\
\text { childhood; } \\
22.2 \% \\
\text { adolescence; } \\
22.2 \% \\
\text { adulthood }\end{array}$ & $\begin{array}{l}\text { F: } 114.6 \\
\text { (11.27); } \\
\text { WASI-II }\end{array}$ & $\begin{array}{l}94.8 \text { White; } 1.7 \\
\text { Black or African } \\
\text { America; } 1.7 \\
\text { Asian; } 1.7 \text { More } \\
\text { than one race; } \\
6.9 \text { Hispanic or } \\
\text { Latino }\end{array}$ & $\begin{array}{l}\text { 3.4 Some high } \\
\text { school; } 6.9 \text { High } \\
\text { school diploma } \\
\text { or GED; } 8.6 \\
\text { Associates } \\
\text { degree; } 46.6 \\
\text { College student; } \\
25.9 \text { Bachelor's } \\
\text { degree; } 8.6 \\
\text { Graduate degree }\end{array}$ & $\begin{array}{l}39.7 \text { Generalized } \\
\text { anxiety disorder; } \\
31.0 \\
\text { Major depressive } \\
\text { disorder; } 17.2 \\
\text { ADHD; } 15.5 \\
\text { Social anxiety } \\
\text { disorder; } 12.1 \\
\text { Obsessive- } \\
\text { compulsive } \\
\text { disorder; } 6.9 \\
\text { Eating disorder; } \\
\text { 5.2 Learning } \\
\text { disorder; } 5.2 \\
\text { Specific phobia; } \\
3.4 \text { Personality } \\
\text { disorder; } 1.7 \\
\text { Bipolar disorder; } \\
\text { 1.7 } \\
\text { Trichotillomania }\end{array}$ & $\begin{array}{l}\text { USA; } \\
\text { Advertisements } \\
\text { distributed via } \\
\text { mental health } \\
\text { clinics and social } \\
\text { media. }\end{array}$ \\
\hline \multirow[t]{2}{*}{$\begin{array}{l}\text { Brown et } \\
\text { al. (2020) }\end{array}$} & $\begin{array}{l}350 \text { ASD }(n= \\
280 \text { F, } 3 \text { M, } 66 \\
\text { O); gender } \\
(n=345 F, 4 \\
M, 1 \text { O); sex }\end{array}$ & $\begin{array}{l}36.21, \\
(10.10), 18- \\
72\end{array}$ & 100 & n.r. & n.r. & 80.9 Caucasian & n.r. & n.r. & $\begin{array}{l}\text { USA; } \\
\text { Advertisements } \\
\text { placed on social } \\
\text { media, online } \\
\text { women's autism } \\
\text { community and } \\
\text { support groups. }\end{array}$ \\
\hline & $\begin{array}{l}322 \text { TD }(n= \\
309 \text { F, } 1 \text { M, } 11 \\
\text { O); gender } \\
(n=322 \mathrm{~F}) ; \\
\text { sex }\end{array}$ & $\begin{array}{l}34.83,(9.93), \\
18-72\end{array}$ & & & & 84.5 Caucasian & & & \\
\hline
\end{tabular}




\begin{tabular}{|c|c|c|c|c|c|c|c|c|c|}
\hline $\begin{array}{l}\text { Cage and } \\
\text { Troxell- } \\
\text { Whitman } \\
(2020)\end{array}$ & $\begin{array}{l}180 \text { ASD }(n= \\
93 \mathrm{~F}, 76 \mathrm{M}, 9 \\
\text { O, } 2 \text { n.r.); } \\
\text { gender }\end{array}$ & $\begin{array}{l}33.89 \\
(11.21), \text { n.r. }\end{array}$ & 87.8 & n.r. & n.r. & $\begin{array}{l}58.9 \text { White- } \\
\text { British; } 26.7 \\
\text { White other } \\
\text { background; } \\
8.3 \text { Mixed or } \\
\text { multi-ethnic; } \\
\text { 3.3 Asian or } \\
\text { British-Asian; } \\
\text { 1.7 Other } \\
\text { ethnicities; } 1.1 \\
\text { Prefer not to } \\
\text { disclose }\end{array}$ & $\begin{array}{l}\text { 6.1 No } \\
\text { qualifications; } \\
10.0 \text { Other } \\
\text { qualifications; } \\
23.4 \text { High school } \\
\text { qualifications; } \\
32.8 \\
\text { Undergraduate } \\
\text { degree; } 23.9 \\
\text { Postgraduate } \\
\text { degree; } 3.9 \\
\text { Preferred not to } \\
\text { say }\end{array}$ & n.r. & $\begin{array}{l}\text { Worldwide; } \\
\text { Advertisements } \\
\text { distributed via } \\
\text { social media, } \\
\text { autism charities and } \\
\text { organisations, and } \\
\text { contacts via the } \\
\text { university disability } \\
\text { service. }\end{array}$ \\
\hline $\begin{array}{l}\text { Hull, Lai et } \\
\text { al. (2020) }\end{array}$ & $\begin{array}{l}306 \text { ASD }(n= \\
182 \mathrm{~F}, 108 \mathrm{M}, \\
16 \mathrm{NB}) ; \\
\text { gender }\end{array}$ & $\begin{array}{l}\text { F: 39.91, } \\
\text { (12.75), n.r.; } \\
\text { M: 46.68, } \\
\text { (13.98), n.r.; } \\
\text { O: 33.50, } \\
\text { (11.74), n.r. }\end{array}$ & 100 & $\begin{array}{l}\text { F: } 34.07 \\
(13.13) ; \\
\text { M: } 37.92 \\
(15.99) ; \\
\text { O: } 23.76 \\
(13.08)\end{array}$ & n.r. & n.r. & $\begin{array}{l}\text { F: } 36 \text { Secondary } \\
\text { school; } 30 \\
\text { Undergrad; } 33 \\
\text { Postgrad; } 1 \text { Not } \\
\text { specified } \\
\text { M: } 35 \text { Secondary; } \\
28 \text { Undergrad; } 35 \\
\text { Postgrad; } 2 \text { Not } \\
\text { specified } \\
\text { Non-Binary = } 66 \\
\text { Secondary; } 17 \\
\text { Undergrad; } 17 \\
\text { Postgrad; } 0 \text { Not } \\
\text { specified }\end{array}$ & n.r. & $\begin{array}{l}\text { Worldwide; } \\
\text { Recruited via CARD, } \\
\text { advertisements } \\
\text { placed on social } \\
\text { media, and word of } \\
\text { mouth. }\end{array}$ \\
\hline
\end{tabular}




\begin{tabular}{|c|c|c|c|c|c|c|c|c|c|}
\hline & $\begin{array}{l}472 \mathrm{TD}(\mathrm{n}= \\
252 \mathrm{~F}, 193 \mathrm{M}, \\
27 \mathrm{O})\end{array}$ & $\begin{array}{l}\text { F: 29.86, } \\
\text { (13.40), n.r. } \\
\text { M: } 30.94 \text {, } \\
\text { (14.78), n.r.; } \\
\text { O: 26.52, } \\
\text { (10.74), n.r. }\end{array}$ & & & & & $\begin{array}{l}\text { F: } 47 \text { Secondary } \\
\text { school; } 28 \\
\text { Undergrad; } 25 \\
\text { Postgrad; } 0 \text { Not } \\
\text { specified; } \\
\text { M: } 47 \text { Secondary } \\
\text { school; } 30 \\
\text { Undergrad; } 23 \\
\text { Postgrad; } 0 \text { Not } \\
\text { specified } \\
\text { N.B.: = } 86 \\
\text { Secondary } \\
\text { school; } 7 \\
\text { Undergrad; 7; } 7 \\
\text { Postgrad }\end{array}$ & & \\
\hline \multirow[t]{2}{*}{$\begin{array}{l}\text { Livingston } \\
\text { et al. } \\
(2020)\end{array}$} & $\begin{array}{l}58 \text { ASD }(n= \\
44 F, 14 M) \\
\text { sex }\end{array}$ & $\begin{array}{l}35.85 \\
(11.53), 18- \\
70\end{array}$ & 100 & 30.14 (13.84) & n.r. & n.r. & $4.66(2.08)^{d}$ & n.r. & $\begin{array}{l}\text { Worldwide; Adverts } \\
\text { placed on social } \\
\text { media and with the } \\
\text { UK National Autistic } \\
\text { Society. }\end{array}$ \\
\hline & $\begin{array}{l}59 \text { TD (social } \\
\text { difficulties not } \\
\text { diagnosed) (n } \\
=51 F, 8 M \text { ) }\end{array}$ & $\begin{array}{l}33.88, \\
(14.83), 18- \\
77\end{array}$ & & & & & $4.68(1.78)^{d}$ & & \\
\hline \multirow[t]{2}{*}{$\begin{array}{l}\text { Robinson } \\
\text { et al. } \\
(2020)\end{array}$} & $\begin{array}{l}278 \text { ASD (n= } \\
163 \text { F, } 104 \text { M, } \\
11 \text { O); n.r. }\end{array}$ & $\begin{array}{l}\text { 36.8, (15.4), } \\
\text { n.r. }\end{array}$ & 100 & n.r. & n.r. & n.r. & n.r. & n.r. & $\begin{array}{l}\text { Worldwide; Online } \\
\text { recruitment system } \\
\text { at University } \\
\text { College London, via } \\
\text { social media, and } \\
\text { CARD. }\end{array}$ \\
\hline & $\begin{array}{l}230 \mathrm{TD}(\mathrm{n}= \\
187 \mathrm{~F}, 40 \mathrm{M}, 3 \\
\mathrm{O})\end{array}$ & & & & & & & & \\
\hline
\end{tabular}




\begin{tabular}{|c|c|c|c|c|c|c|c|c|c|}
\hline $\begin{array}{l}\text { Cook et al. } \\
(2021)\end{array}$ & $\begin{array}{l}17 \text { ASD }(n=8 \\
F, 6 M, 3 A G) \\
\text { gender }\end{array}$ & $\begin{array}{l}44.53 \\
(12.03), 25- \\
64\end{array}$ & 100 & $41.71(12.18)$ & $\begin{array}{l}112.47 \\
(4.65) ; \\
\text { TOPF }\end{array}$ & $\begin{array}{l}88.2 \text { White; } 5.9 \\
\text { Mixed; } 5.9 \\
\text { Hispanic }\end{array}$ & $\begin{array}{l}\text { 5.8 A-levels; } 44 \\
\text { Bachelor's } \\
\text { degree; } 41.2 \\
\text { Master's } \\
\text { degree; } 5.8 \text { PhD }\end{array}$ & n.r. & $\begin{array}{l}\text { UK; Recruited via } \\
\text { adverts } \\
\text { disseminated on } \\
\text { social media and } \\
\text { through autism } \\
\text { support groups. }\end{array}$ \\
\hline $\begin{array}{l}\text { Hull et al. } \\
\text { (2021) }\end{array}$ & $\begin{array}{l}305 \text { ASD }(n= \\
181 \mathrm{~F}, 104 \mathrm{M}, \\
18 \mathrm{NB}) ; \\
\text { gender } \\
\text { ( } \mathrm{n}=283 \\
\text { cisgender) }\end{array}$ & $\begin{array}{l}41.90(\mathrm{Cl}: \\
40.37,43.43)^{f}, \\
18-75\end{array}$ & 100 & n.r. & n.r. & n.r. & n.r. & $\begin{array}{l}56.7 \text { Generalised } \\
\text { anxiety disorder; } \\
54.4 \text { Depression } \\
\text { disorder; } 2.3 \\
\text { Social anxiety } \\
\text { disorder/social } \\
\text { phobia diagnosis } \\
\end{array}$ & $\begin{array}{l}\text { Worldwide; } \\
\text { Recruited via CARD } \\
\text { and adverts placed } \\
\text { on social media and } \\
\text { with relevant UK } \\
\text { based autism } \\
\text { charities. }\end{array}$ \\
\hline $\begin{array}{l}\text { Perry et al. } \\
\text { (2021) }\end{array}$ & $\begin{array}{l}223 \mathrm{ASD}(\mathrm{n}= \\
130 \mathrm{~F} ; 53 \mathrm{M} ; \\
39 \mathrm{NB} / \mathrm{O} ; 1 \\
\text { Prefer not to } \\
\text { say); gender }\end{array}$ & $\begin{array}{l}34.19(11) \\
18-65\end{array}$ & 100 & $28.67(13.31)$ & n.r. & $\begin{array}{l}92.8 \text { White; } 3.1 \\
\text { Mixed; } 1.3 \\
\text { Other; } 0.4 \\
\text { Black; } 2.2 \\
\text { prefer not to } \\
\text { say }\end{array}$ & $\begin{array}{l}3.6 \text { None; } 11.7 \\
\text { High school; } 22.4 \\
\text { College/sixth } \\
\text { form; } 4.9 \\
\text { Trade/vocational; } \\
28.7 \\
\text { Undergraduate } \\
\text { degree; } 17 \\
\text { Masters degree; } \\
\text { 6.7 Doctorate; } \\
\text { 2.2 Other; } 2.7 \\
\text { preferred not say }\end{array}$ & n.r. & $\begin{array}{l}\text { Worldwide; } \\
\text { Recruited via } \\
\text { adverts shared on } \\
\text { researcher's social } \\
\text { media accounts, } \\
\text { emails to UK-based } \\
\text { autism community } \\
\text { groups, charities, } \\
\text { and word of mouth. }\end{array}$ \\
\hline \multicolumn{10}{|c|}{ Child/Adolescent Studies } \\
\hline $\begin{array}{l}\text { Rynkiewcz } \\
\text { et al. } \\
\text { (2016) }\end{array}$ & $\begin{array}{l}33 \text { ASD }(n= \\
16 \mathrm{~F}, 17 \mathrm{M}) \\
\text { sex/gender }\end{array}$ & $\begin{array}{l}\text { F: 8.06, } \\
\text { (1.57), n.r.; } \\
\text { M: 8.23, } \\
\text { (2.05), n.r. }\end{array}$ & 100 & n.r. & $\begin{array}{l}F(n=13): \\
109.58 \\
(11.70) ; \\
M(n=16): \\
112.31 \\
(13.10) ; \\
\text { medical } \\
\text { records }\end{array}$ & n.r. & & n.r. & $\begin{array}{l}\text { Poland; Recruited } \\
\text { via child and } \\
\text { adolescent mental } \\
\text { health services and } \\
\text { autism clinics. }\end{array}$ \\
\hline
\end{tabular}




\begin{tabular}{|c|c|c|c|c|c|c|c|c|}
\hline $\begin{array}{l}\text { Parish- } \\
\text { Morris et } \\
\text { al. (2017) }\end{array}$ & $\begin{array}{l}65 \operatorname{ASD}(n= \\
16 \text { F, } 49 M) \\
\text { sex }\end{array}$ & $\begin{array}{l}\text { F: 10.66, } \\
(1.55), \text { n.r.; } \\
M: 9.73, \\
(2.16), \text { n.r. }\end{array}$ & 100 & n.r. & $\begin{array}{l}F: 104 \\
(13) ; M: \\
106(14) ; \\
\text { DAS-II }\end{array}$ & 85 White & n.r. & $\begin{array}{l}\text { USA; Recruitment } \\
\text { via the Centre for } \\
\text { Autism Research at } \\
\text { the Children's } \\
\text { Hospital of } \\
\text { Philadelphia. }\end{array}$ \\
\hline & $17 \mathrm{TD}$ & $\begin{array}{l}\text { 11.32, } \\
(2.21), \text { n.r. }\end{array}$ & & & $\begin{array}{l}104(15) ; \\
\text { DAS-II }\end{array}$ & n.r. & & \\
\hline $\begin{array}{l}\text { Ormond et } \\
\text { al (2018) }\end{array}$ & $\begin{array}{l}236 \text { ASD }(n= \\
98 F, 138 M) \\
\text { sex }\end{array}$ & $\begin{array}{l}\text { n.r., (n.r.), 5- } \\
19\end{array}$ & 100 & n.r. & n.r. & n.r. & $\begin{array}{l}\text { F: } 42.9 \text { co-occurring } \\
\text { diagnosis } \\
\text { M: } 39.1 \text { co-occurring } \\
\text { diagnosis }\end{array}$ & $\begin{array}{l}\text { Australia; Clinic- } \\
\text { based sample via } \\
\text { specialist autism } \\
\text { clinic. }\end{array}$ \\
\hline $\begin{array}{l}\text { Ratto et al. } \\
\text { (2018) }\end{array}$ & $\begin{array}{l}228 \text { ASD (n = } \\
114 \text { F, } 114 \\
M) ; \operatorname{sex}\end{array}$ & $\begin{array}{l}\text { F: 10.11, } \\
(2.19), \text { n.r.; } \\
M: 10.12, \\
\text { (2.15), n.r. }\end{array}$ & 100 & n.r. & $\begin{array}{l}\text { F: 101.16 } \\
(19.14) ; \\
\text { M: } \\
101.03 \\
(18.67) \\
\text { WASI; } \\
\text { WASI-II; } \\
\text { WISC-IV; } \\
\text { WISC-V; } \\
\text { WAIS-IV; } \\
\text { WPPSI-IV; } \\
\text { DAS-II }\end{array}$ & $\begin{array}{l}73 \text { White; } 7 \\
\text { Black; } 4 \text { Asian; } 5 \\
\text { Latino/a; } 10 \\
\text { Other/unknown }\end{array}$ & n.r. & $\begin{array}{l}\text { USA; Clinic-based } \\
\text { and research- } \\
\text { recruited samples } \\
\text { via the Centre for } \\
\text { Autism Spectrum } \\
\text { Disorders at } \\
\text { Children's National, } \\
\text { the National } \\
\text { Institute of Mental } \\
\text { Health Laboratory of } \\
\text { Brain and Cognition, } \\
\text { the Centre for } \\
\text { Autism Research at } \\
\text { Children's Hospital } \\
\text { of Philadelphia, and } \\
\text { research and clinical } \\
\text { programs at Virginia } \\
\text { Tech, including the } \\
\text { Centre for Autism } \\
\text { Research. }\end{array}$ \\
\hline
\end{tabular}




\begin{tabular}{|c|c|c|c|c|c|c|c|c|}
\hline $\begin{array}{l}\text { Livingston, } \\
\text { Colvert, et } \\
\text { al. (2019) }\end{array}$ & $\begin{array}{l}136 \text { ASD }(n= \\
24 \mathrm{~F}, 112 \mathrm{M}) \\
\text { gender }\end{array}$ & $\begin{array}{l}13.28, \\
(0.93), 10-15\end{array}$ & 74.3 & n.r. & $\begin{array}{l}\text { low } \\
\text { comp: } \\
85.54 \\
\text { (20.60); } \\
\text { high } \\
\text { comp: } \\
94.6 \\
(17.58) \\
\text { deep } \\
\text { comp: } \\
101.88 \\
(14.75) ; \\
\text { unknown: } \\
97.11 \\
\text { (16.08); } \\
\text { WASI }\end{array}$ & n.r. & n.r. & $\begin{array}{l}\text { UK; Post-hoc } \\
\text { analysis of data. } \\
\text { Participants were } \\
\text { originally recruited } \\
\text { for the Twins Early } \\
\text { Development Study } \\
\text { and identified via } \\
\text { birth records. }\end{array}$ \\
\hline & 67 TD & & & & & & & \\
\hline $\begin{array}{l}\text { Corbett et } \\
\text { al. (2020) }\end{array}$ & $\begin{array}{l}161 \text { ASD }(n= \\
46 \mathrm{~F}, 115 \mathrm{M}) \\
\text { sex }\end{array}$ & $\begin{array}{l}\text { F: 12.93, } \\
(1.80), 10: 0- \\
16: 11 ; \\
\text { M: } 12.78 \\
(2.03)\end{array}$ & 100 & n.r. & $\begin{array}{l}\text { F: } 97.48 \\
(17.3) ; \\
\text { M: } 98.98 \\
(18.5) ; \\
\text { WASI-II }\end{array}$ & n.r. & n.r. & $\begin{array}{l}\text { USA; Post-hoc } \\
\text { analysis of data. } \\
\text { Data originally } \\
\text { collected as part of a } \\
\text { multisite } \\
\text { randomized clinical } \\
\text { trial targeting social } \\
\text { skills. No further } \\
\text { recruitment details } \\
\text { reported. }\end{array}$ \\
\hline $\begin{array}{l}\text { Hull, } \\
\text { Petrides \& } \\
\text { Mandy } \\
\text { (2020) }\end{array}$ & $\begin{array}{l}58 \text { ASD }(n= \\
29 \text { F, } 29 \text { M); } \\
\text { n.r. }\end{array}$ & $\begin{array}{l}14.48, \\
(1.74), 13-18\end{array}$ & 100 & n.r. & $\begin{array}{l}100.85 \\
\text { (15.98); } \\
\text { WASI-II }\end{array}$ & n.r. & n.r. & $\begin{array}{l}\text { UK; Recruited via } \\
\text { local National Health } \\
\text { Service services, } \\
\text { advertisements } \\
\text { placed on social } \\
\text { media, and word of } \\
\text { mouth. }\end{array}$ \\
\hline
\end{tabular}




\begin{tabular}{|c|c|c|c|c|c|c|c|c|}
\hline \multirow[t]{2}{*}{$\begin{array}{l}\text { Jorgenson } \\
\text { et al. } \\
(2020)\end{array}$} & $\begin{array}{l}78 \text { ASD }(n= \\
23 \text { F, } 55 \text { M); } \\
\text { sex }\end{array}$ & $\begin{array}{l}15.03(1.67) ; \\
13-18^{\mathrm{b}}\end{array}$ & 100 & n.r. & n.r. & n.r. & n.r. & $\begin{array}{l}\text { USA; Recruited via } \\
\text { specialty clinic for } \\
\text { autism and } \\
\text { neurodevelopmental } \\
\text { disorders; SPARK } \\
\text { database; } \\
\text { advertisements } \\
\text { placed on social } \\
\text { media and local } \\
\text { university email } \\
\text { announcement. }\end{array}$ \\
\hline & $\begin{array}{l}62 \mathrm{TD}(\mathrm{n}=35 \\
\mathrm{F}, 27 \mathrm{M}) ; \text { sex }\end{array}$ & $15.31(1.65)$ & & & & & & \\
\hline \multirow[t]{2}{*}{$\begin{array}{l}\text { Wood- } \\
\text { Downie et } \\
\text { al. (2020) }\end{array}$} & $\begin{array}{l}40 \text { ASD/ASD } \\
\text { traits }(n=18 \\
F, 22 \mathrm{M}) ; \\
\text { sex/gender }\end{array}$ & $\begin{array}{l}\text { F: } 10.12, \\
(1.43), 7.92- \\
13.42 \\
M: 10.08, \\
(1.75), 8.08- \\
13.92\end{array}$ & 45 & n.r. & $\begin{array}{l}\text { F: } 99.00 \\
(15.68) ; \\
\text { M: 99.55 } \\
\text { (17.58); } \\
\text { WASI-II }\end{array}$ & n.r. & n.r. & $\begin{array}{l}\text { UK; Recruited via } \\
\text { Special Educational } \\
\text { Needs Coordinators } \\
\text { and/or Head } \\
\text { Teachers from } 16 \\
\text { mainstream primary } \\
\text { schools and three } \\
\text { mainstream } \\
\text { secondary schools in } \\
\text { the South of } \\
\text { England. }\end{array}$ \\
\hline & $\begin{array}{l}44 \mathrm{TD}(\mathrm{n}=22 \\
\mathrm{F}, 22 \mathrm{M}) ; \\
\text { sex/gender }\end{array}$ & $\begin{array}{l}F: 9.62, \\
(1.01), 8.08- \\
11.5 \\
M: 10.50, \\
(1.40), 8.58- \\
14.42\end{array}$ & & & $\begin{array}{l}\mathrm{F}: 101.41 \\
(14.18) \mathrm{n} ; \\
\mathrm{M}: \\
107.59 \\
(12.36)\end{array}$ & & & \\
\hline
\end{tabular}




\begin{tabular}{|c|c|c|c|c|c|c|c|c|}
\hline $\begin{array}{l}\text { Bernardin } \\
\text { et al. } \\
(2021)\end{array}$ & $\begin{array}{l}78 \text { ASD }(23 \mathrm{~F}, \\
55 \mathrm{M}) ; \text { sex }\end{array}$ & $\begin{array}{l}15.03(1.68) \\
13-18^{\mathrm{b}}\end{array}$ & 100 & n.r. & n.r. & n.r. & n.r. & $\begin{array}{l}\text { USA; Recruited via } \\
\text { specialty clinic for } \\
\text { autism and } \\
\text { neurodevelopmental } \\
\text { disorders; SPARK } \\
\text { database; } \\
\text { advertisements } \\
\text { placed on social } \\
\text { media and local } \\
\text { university email } \\
\text { announcement. }\end{array}$ \\
\hline & $\begin{array}{l}62 \mathrm{TD}(35 \mathrm{~F}, \\
27 \mathrm{M}) ; \operatorname{sex}\end{array}$ & $15.31(1.65)$ & & & & & & \\
\hline $\begin{array}{l}\text { Jedrzewska } \\
\text { \& Dewey } \\
\text { (2021) }\end{array}$ & $\begin{array}{l}42 \text { ASD (13 F, } \\
26 \mathrm{M}, 3 \mathrm{O}) ; \\
\text { gender }\end{array}$ & $\begin{array}{l}14.1^{g} \text { (n.r.), } \\
13-19^{b}\end{array}$ & 100 & n.r. & n.r. & n.r. & n.r. & $\begin{array}{l}\text { UK; Recruited from } 5 \\
\text { schools in London. }\end{array}$ \\
\hline
\end{tabular}

\footnotetext{
Note: n.r. = not reported; $F=$ female; $M=$ male; $T G=$ transgender; $N B=$ non-binary; $A G$ = agender/gender neutral; $O=$ other genders (study authors reported a range of genders included as 'other' such as non-binary, genderfluid, transgender male, and transgender female); $D=$ formally diagnosed; S.I. = self-identifying; Low Comp = low compensation group; High Comp = high compensation group; Deep Comp = deep compensation group; Unknown= unknown group; WASI = Wechsler Abbreviated Scales of Intelligence; WASI-II = Wechsler Abbreviated Scales of Intelligence Second Edition; WISC-IV: = Wechsler Intelligence Scale for Children Fourth Edition; WISC-V = Wechsler Intelligence Scale for Children Fifth Edition; WPPSI-IV = Wechsler Preschool and Primary Scale of Intelligence Fourth Edition; DAS-II = Differential Ability Scales, Second Edition; ToPF = Test of Premorbid Functioning; CARD = Cambridge Autism Research Database; SPARK = Simons Foundation Powering Autism Research for Knowledge

a age range for total ASD sample.

b age range for total ASD and TD sample combined.

${ }^{c}$ location based on first authors institution if location of study participants not specified in the article.
} 
${ }^{d}$ mean and (SD) for International Standard Classification of Education.

${ }^{\mathrm{e}}$ mean and (SD) calculated based on ASD and TD sample combined.

${ }^{\mathrm{f}} 95 \%$ confidence interval.

${ }^{\mathrm{g}}$ based on ASD and TD sample combined. 